A publication of the Muma College of Business | University of South Florida

\begin{tabular}{lll}
\hline Volume 6 & Number 14 & 15 JULY 2021 \\
\hline
\end{tabular}

EDWARD EMMANUEL, JAMIE CUDDEN, MATTHEW MULLARKEY

\title{
WHEN SMART BINS MEET A SMART CITY ${ }^{1}$
}

"We've deployed smart bins across the city in a variety of ways. And, reactions have been very positive! But the main question still remains... Are they simply a 'tech' alternative to everyday bins, or are there further opportunities to be explored?"-Simon Brock

The sky was overcast, with bouts of light showers expected throughout the day. In other words, nothing unusual for a cool January's day in Dublin, Ireland. Simon Brock, Administrative Officer of Dublin City Council's Waste Management Services was about to look over details of the day's waste collection in Dublin's Smart Docklands district (See Exhibit 1). Simon had worked his way through the waste management section over the years, and with it, learned the ins and outs of navigating its processes. Of particular interest in recent times, was the advent of the 'smart bin', and how it was touted to be transformational for his operations. After comparing multiple products, Simon and his colleagues chose to invest in specialised solar compacting smart bins, to help optimise public waste collections across the city (See Exhibit 2). A tender to purchase these solar compacting smart bins was drafted in collaboration with Dublin City Council's smart city department. Included in this tender was the 24-month trialling of novel innovation services, under a 'Smart Bins as a Service' leasing payment plan. Though the primary focus for Simon was to use his capital budget to optimise waste management services, the trialling of these novel services was strongly supported by both the smart city department, and the chief executive's office of the city council. Simon was open to exploring this innovation services model, but was grappling with a number of longer term concerns he hoped would be answered in the months ahead.

For example, considering the capital investment already put in, was there enough of a return on investment to purchase even more smart bins? Also, could the differing capital and operational spending between outright purchasing (happening currently), and the alternative innovation services leasing payments prove too disruptive? At the same time, he thought about some members of the public who have long complained about overflowing bins, pest interferences, and other hazards involving public waste. Surely, scaling up usage of the smart bins will help assuage these concerns? And finally, if waste management did not gain from paying for these 'innovation services', then who would? Along with over 400 operational staff attached to waste management operations (See Exhibit 3), he wondered how their roles could be affected if there were plans to adopt these smart bins for the rest of the over 3000 public bins scattered across the city.

Simon and his team had to carefully assess this interplay among people, processes, and technology, in order to manage the often-conflicting expectations that came with fostering innovation in traditional spaces.

${ }^{1}$ Copyright (C 2021, Edward Emmanuel, Jamie Cudden, Matthew Mullarkey. This case was prepared for the purpose of class discussion, and not to illustrate the effective or ineffective handling of an administrative situation. Names and some information have been disguised. This case is published under a Creative Commons BY-NC license. Permission is granted to copy and distribute this case for non-commercial purposes, in both printed and electronic formats. 


\title{
Waste Generation in Global Cities, Dublin City, and Ireland
}

Cities across the world produced up to 10 billion tonnes of garbage annually, according to the UN's most recent large-scale estimate carried out back in 2015, as reported by Let's Do It Foundation (See Exhibit 4). This figure has likely increased over the past 5 years. Needless to say, consumption and corresponding waste output is among the highest the world has seen, where urban environments play a significant role in. As cited by the World Economic Forum in 2019 (See Exhibit 5):

\begin{abstract}
"As countries become more prosperous, their trash cans become increasingly full. Rapid urbanisation and population growth adds to the problem, making collection increasingly problematic and sites for treatment harder to locate. For many local administrations, particularly in poorer settings, waste management can be the single biggest expenditure."
\end{abstract}

In Dublin city alone, approximately 18,000 tonnes of litter and street cleaning waste is removed annually from $115 \mathrm{~km}$ squared of street space and a network of more than 3,000 public waste bins. Also, more than 2,200 tonnes of mixed dry recyclables are collected at Bring Centres annually and over 9,000 tonnes of glass is recovered through the network of bottle banks, while almost 1,000 tonnes of green waste is recycled for composting each year. A further 4,500 tonnes of recycling of various waste streams are recovered through the 2 Civic Amenity recycling facilities. Looking at things from a countrywide level, people living in Ireland produced over 15 million tonnes of waste every year. The average amount of waste produced per person in 2016 was $580 \mathrm{~kg}$ of municipal waste (See Exhibit 6) - well above the European average of $487 \mathrm{~kg}$ - as monitored by the Irish Environmental Protection Agency.

\section{Local government and waste management}

As it stands, local government councils across Ireland are represented through two distinct areas, mainly the reserved functions (for the elected council), and the executive functions (for the chief executive).

Reserved functions remain in the sole jurisdiction of elected councillors in the form of policy decisions, and resolutions passed in council meetings. Specifically, these included passing annual budgets, determining housing policy decisions, and determining policies on environmental protection, among others.

On the converse, the executive functions, led by the chief executive, seek to enact and execute the day-today operational will and needs of the elected council.

Historically, the local administration of housing, health, and sanitation, proved transformative to the lives of ordinary citizens. As town centres continued to become the focal attraction point for different commercial opportunities, the state of sanitation took on a renewed focus. The evolution of this departmental work has grown into what we now know as 'Waste Management Services' among councils across Ireland.

\section{Overall Dublin city waste management set-up}

The delivery of waste management service in Dublin City is structured on providing a range of services to all areas of the city. The city itself is broken up into 5 administrative areas (See Exhibit 7), which includes its city centre core. Each area has its own local management team and operatives in charge. Depending on the size of the assigned administrative area, there are up to 10 inspector/supervisory staff in each local management team, and up to 66 operational staff involved per operational area i.e. over 400 operational staff in total not including inspectors, wardens, maintenance technicians, and engineers. Cleaning and bin collection routes are defined locally. Where standard bins are in place, they would be 
emptied at least once daily regardless of their use. This can increase up to 6 times daily in the city centre core.

Each operational staff member is usually assigned to the same particular work stream and tasks, so that there is a skills build-up (on that stream and task) to improve efficiency. There are a lot of layers on deciding who gets assigned to what task, such as needing the appropriate training, and administration (usually based on seniority) on who gets priority with different work streams and tasks. Some of these include graffiti removal, operating a street washer machine/vehicle, and general street sweeping. Additionally, these work streams can be broken up into three separate time shifts mainly, morning: 6am to $2 \mathrm{pm}$, mid-day to night: $2 \mathrm{pm}$ to $10 \mathrm{pm}$, and overnight to morning shift: from $10 \mathrm{pm}$ to $6 \mathrm{am}$. The overnight to morning shifts are concentrated in the city centre, where waste management services run over a $24-$ hour period.

A specialised 'side-loader' caged vehicle is used by the operational staff for public waste collection (See Exhibit 8). These vehicles were chosen precisely because of their smaller frames and ability to drive through leaner, more narrow streets. This in contrast to larger refuse collection trucks (See Exhibit 9), which are too large to turn into the narrower lanes, and thus require operational staff to cover larger walking distances.

\section{Waste management's collaboration with the smart city department}

As mentioned previously, the support from the smart city department and chief executive's office was instrumental in exploring and testing products and services that would help improve productivity, not just for waste management, but other departments in the city council. An important distinction made with the smart city department is that a macro-level corporate view is adopted by default, gunning for improvements across various departments. This 'breaking down of silos' helps to incubate the idea that innovation at its base, is cross-functional, and that the advent of the smart cities movement will see a further breaking down of operational, political, and productivity barriers among previously segregated functional departments of a municipality. The smart city department in Dublin city council works by helping to curate and create unique pathways, to trial promising technology solutions from the market in a cost-effective manner, in order to fully assess its capacity for longer-term and wider-spread use. The department operates much like a project-management office (PMO) where innovative projects that have showcased exceptional results, would have to be 'seeded' back into the other operational departments, or business as usual (BAU), in order to realise its fullest benefits. In this case, the innovation services proposed with the smart bins as a service contract were cross-functional in nature, and provided benefits beyond the waste management department.

\section{Feedback from Dublin city's public}

When the first smart bins were deployed as part of trials, public sentiment was overwhelmingly positive. A big concern cited with the existing architecture of most public bins was their open-air accessible nature (See Exhibit 10). This helped facilitate easy disposal of waste from members of the public, but also invited the attention of various pests, critters, and birds, to access the bin's contents. The smart bins proved themselves as very robust vehicles to prevent such pest interference of disposed waste. The smart bin's closed frame, as well as its architecture on how its opening handle did not open directly to the contents of the bin, was noted to help prevent pests from accessing the waste. Another key piece of public feedback was the desire to deposit waste without having to touch any part of the receptacle. This was onboarded in the next iteration of smart bins, where a simple connected foot pedal was installed, acting as a 
mechanism to open the smart bin's door handle to deposit waste, without having to use your hands pull it open (See Exhibit 11). The popularity of the smart bins has also been perceived as a sign of 'renewed investment' in areas they are deployed in. There was also however, a minority of negative feedback received: like how their larger than average sizes and clunky exteriors took up more space than the norm; and how their aesthetic did not 'fit the look' of certain districts or historical areas.

In terms of complaints received on other issues, the highest numbers were attributed to illegal dumping (41\%), general street waste (18\%), and community area cleanliness (12\%) (See Exhibit 12). The complaint numbers showcased city waste management's sheer impact on public perception, and the pressing need to upkeep and maintain general levels of cleanliness. In particular, how illegal disposing has been costly, both on a societal and financial level.

Additional methods to improve the experience of citizens providing feedback, especially the state of public bins (e.g. whether it is overflowing, or has been damaged), had been pushed through earlier by the public bin unique identifier campaign. All public bins in Dublin city had been fitted with a unique 'QR code' that captured information about that bin (See Exhibit 13). It served as a channel for people to scan a specific bin's code, in order to leave feedback about its condition. This enabled an added avenue for communication on top of the traditional phone calls or emails. This measure still left some operational gaps, which however, were later alleviated with the deployment of smart bins.

\section{The General Set-Up for Smart Bins}

The primary set up for smart bins would be to either do a one-to-one swap with a normal bin where additional capacity is the primary requirement, or reduce the overall number of bins by replacing a cohort of existing bins with an installation of smart bins that provides overall additional capacity with less units. Conventionally, a suite of smart bins that replace normal public bins in an area would prove highly beneficial based on two primary value-added features:

\section{Significantly increase waste holding capacity for each bin}

Depending on type, model, and brand, up to 8 times of waste holding capacity can be obtained through a smart bin compared to an ordinary bin of the same size. This would be done through an automated compactor that compresses the waste on an hourly average, powered by photovoltaic solar panels on the roof of the bin. Hence, there is no added infrastructure cost to connect it to a power source to enable the compactor. Improving capacity for each bin also helps reduce frequency of collection, with an associated reduction in vehicle usage, $\mathrm{CO} 2$ emissions and travel time. These values have a multiplier effect based on the total number of smart bins that have replaced normal bins, saving significant amounts of time for the involved operational staff who carry out bin collections.

\section{Indicate fullness levels for each bin}

The smart bins have a powerful feature that indicates its level of fullness in real time. This allows management and operational staff to see how much waste each bin contains in terms of percentages. As a result, they are also able to see which bins have reached, or are about to reach, their capacity. This information is accessed through an internet-enabled device such as a smart phone, which opens up an online dashboard digital map (See Exhibit 14), showing the location of each bin. Alert notifications can also be requested for specific accounts and devices when a chosen bin reaches its capacity. This enables highly adaptable waste collection planning that functions on a 'needs only' basis, avoiding collection of bins that are yet to reach their capacity. The bins also indicate when their door handles are 'jammed', or left open with items of obstruction, allowing operational staff to intervene and get it operating again as soon as convenient. 


\section{Alternative retrofit technology for fullness levels}

As mentioned earlier about comparing multiple product types before choosing to purchase the solar compactor smart bins, Simon and his team found alternative solutions that allowed retrofitting sensors onto existing public bins. These retrofit sensors would indicate when their bins had reached capacity. The biggest issue with these retrofit variations were how capacity could be reached very quickly without the compacting feature of the chosen smart bins. This would hence, potentially notify waste management staff to clean bins in high footfall areas as often as once every few hours, making it highly inefficient in terms of the number of collections incurred.

\section{Overall benefits}

When both of these value added features work in tandem, operational staff are able to significantly reduce the frequency of unnecessary bin collections by as much as $85 \%$. When starting the collection day, these features will allow staff to identify only the most necessary bins that need to be collected, and their locations. This will allow staff to plan the most efficient and optimised collection routes. In what would have been a lengthy multiple-hour affair to collect waste from all bins everyday, the collection process in a designated area could be shaved to as little as 1/10th the time when smart bins are introduced to replace normal bins (See Exhibit 15). In addition to the above waste management functions, the smart bins would also bring value through other key exploratory elements such as:

- Potential advertising opportunities on the sides of these bins where revenue can be shared with the city council (See Exhibit 16). The revenue made would be used to offset the leasing cost of the smart bins, which goes a long way to making the innovation services contract more costeffective. In addition, the bins could be used for key community messaging without having to pay expensive advertising rates with alternative mediums. This could come in the form of waste management oriented messages such as, "Reduce, Reuse, Recycle"; and "Pick up after your dog's poo, no one's doing it for you."; as well as other topical community messages like the "Docklands is back in business" campaign launched in response to Covid-19.

- Trialling sensor technologies to capture footfall and air quality metrics among other useful and novel datasets (See Exhibit 17). Footfall sensors capturing data would be able to help for example, by informing waste management as to when peak periods for pedestrians were, and assigning the appropriate number of waste collection and street cleaning staff in response.

- Hosting telecom radio equipment for existing, as well as next generation cellular coverage like 4GLTE and 5G (See Exhibit 18). In an environment where mobile 'blackspots' continue to appear throughout a urban environment, the smart bins are in prime positions to help alleviate this mobile congestion by hosting the right equipment.

- Hosting WiFi connectivity (See Exhibit 19); Another addition that contributes to the overall 'connectivity' in an area, in the instance where an individual does not have access to mobile data internet (e.g. tourists)

- Exploring analytical research opportunities from the data collected from these various sources. 


\section{Simon's internal discussions with colleagues}

Though the value of the smart bin was quite clear for Simon and his team, as well as benefits to citizens, there were several other important issues to consider when it came to adopting smart bins in Dublin city on a wider-scale. Above all else, cost being the main concern. The smart bins in a word, were expensive, costing as much as 5 to 8 times the price of existing bins. Operational cost-savings would thus, have to be demonstrated thoroughly, as well as overcome key factors as detailed in the following:

\section{The case for operational staff}

As mentioned, a majority of operational staff that collected waste from public bins are permanent employees. Meaning there were no redundancy layoffs, and that termination could only happen in extenuating circumstances. There were no specific stipulations in contracts, other than to meet the needs of the department they were assigned to. In this instance, the waste department decides best on how to assign the labour resources in a most efficient manner. If a role had been found to be redundant, a reassignment of the staff member would be made. In other words, most 'role-redundancies' would see reassignment of the staff member to a role that was facing demand - insofar there was no significant skills gap. Hence, what may be construed as a simple cost-saving equation between reducing manual labour for waste collection, and in response, increasing the use of smart bins in replacement of normal public waste bins, was simply not the case.

A common point made was that compared to the multi-functional capacity of operational staff, the smart bins had much less dimensions, even when accounting for its additional 'value add-on' service contract features. The primary fact being that there would always be areas for improvement in the long' laundry list' of waste management tasks. This included general street cleaning, street washing, graffiti removal, chewing gum removal, dog fouling removal, leaves sweeping, ramping up recycling collection, more illegal dumping removal, and many more. Staff could also be re-deployed to increase activity in off-peak periods, such as the $2 \mathrm{pm}$ to $10 \mathrm{pm}$, and $10 \mathrm{pm}$ to $6 \mathrm{am}$ shifts, as well as areas that traditionally received less frequency of service, primarily outside the city centre.

\section{Adequate equipment and training}

Perhaps an often overlooked issue is taking into account the technologies that enable incorporating new age solutions such as smart bins. The solution, as mentioned, showcased locations of the smart bins overlaid on a digital map. In order to properly display such a map, it had to be displayed on a device that had sufficient processing capability and screen dimensions. This could come in the form of a smartphone or tablet, especially when working on the go. This brings additional financial cost to the department, having to purchase, manage, and replace such devices. Additionally, more training sessions and refresher classes would be needed in order to cater for the increased reliance on the smart bin solution suite - once again, feeding into department resources.

\section{Illegal dumping and smart bins}

As mentioned earlier, there was the ever-looming issue of illegal dumping of waste by certain segments of the public. Waste that would otherwise have been meant for the residential collection system, gets dumped or left by the way-side of public bins instead. Though the technological advantages of the smart bins enable compacting and increased capacity, it also unintentionally accommodates added illegal dumping from residents. As a result, if illegal dumping continues unabated, to the extent it eclipses the larger capacities of the smart bins, the issue will persist. More smart bins do not solve the crux of the issue, which is to address behavioural change. Other mitigation strategies will still be needed. 


\section{Damage and graffiti on purchased smart bins}

Another issue highlighted was the case of damage and graffiti being carried out on the purchased smart bins. Instances have been recorded of doors being pulled apart by vandals, and repairs then having to be made. Repairs and graffiti removal may cost as much 1000 EUR per incident. These costs continue to add up over the months, where remediation becomes an unofficial add-on to the purchasing price. Hence, there has been increased debate on the actual fiscal benefits associated with purchasing the smart bins outright, compared to the innovative leasing contract that allows add-ons for damage warranties and full serviceability of bins with maintenance, repairs, as well as replacements included. As mentioned, the leasing option also included an all-inclusive advertising platform operated by the distributors, which provided ancillary revenue to help alleviate annual leasing cost. This advertising model also ensured that any graffiti was removed as part of the fixed leasing contract payments.

\section{Capital and operational expenditure}

All of these cost considerations for smart bins however, have to be seen through the lens of a more fundamental issue of local government funding. Mainly, the clear distinction made between a municipality's capital and operational budget. Usually, each city council department puts forward their existing and newly expected increase in operational costs (such as rents, leases, salaries, and utilities), to the chief executive's department. This is then scrutinised and approved on a departmental level, as well as overall budget level, before being put forward to councillors for approval. There are 63 democraticallyelected councillors representing Dublin's city council. These councillors would go through the prospective budget requests, before deciding to approve them 'as is', or ask for revisions. However, this process is solely for operational budgeting. Capital budgeting is discussed in a completely separate Corporate Policy Group (CPG), though they are ultimately sent to the same councillors for approval. In essence, capital and operations expenditure are seen as separate entities. Complications and complexities arise when trying to reconcile between these two budgets. For example, a department that reduces its capital expenditure in a given year, does not see that income re-assigned to its operational budget. Hence, Simon and his team have adapted to a system that has viewed these two budgets as distinct, and that justification for new spending on innovation has almost always had to come from the CPG and capital spending (See Exhibit 20). The fact of course, that commercial business models from vendors had begun to shift from 1-time payment for outright purchasing of a solution, to recurring revenue payments under a services (leasing) contract, have not begun to impact how budgets are assigned in this operational-capital split. Acknowledgment of this would have to be made within local government, in order to address the changing landscape where a solution could become fast 'out of date' in a matter of months, and that outright purchasing would leave such a department increasingly exposed.

\section{Visual aspects}

Simon and his team also have the aesthetics of the smart bins to consider. The conventional look of the different smart bins on the market tend to lean on the side of 'futuristic', helping to sell the image of what a smart city should look like. This specific visual aesthetic however, does not always meet local needs. For example, in Dublin city, there are historical areas around the 'Guinness Brewery' and 'Georgian Squares' that call for more appropriately styled street furniture to match up with their aesthetics. Tourists and visitors come to such historical districts with preconceived notions on how they should look like, and hence, efforts to continue marketing and maintaining such locations as cultural hubs would persist in order to grow their vibrant commercial opportunities. 


\section{A more holistic corporate approach to service delivery}

Finally, the assessment of the additional add-ons from the smart bin service contracts, at first glance, included value propositions that did not exactly contribute to the key point indicators of the waste management department. For example, trialling sensor technologies that captured datasets such as footfall (i.e. the amount of pedestrian traffic in an area), did not contribute directly to objectives such as 'reducing illegal dumping' in an area. They could however, contribute to this goal indirectly. In this sense, a count of footfall with time signatures would help to educate the waste management department on the usual periods that illegal dumping occurred in an area, where preventive measures could then be applied at those higher-peak times. Likewise, the addition of a 'radio frequency cabinet' in your smart bin to host mobile equipment, may not contribute directly to improving waste collection efficiency. But once again, when looked at indirectly, it does prevent incidences of connectivity 'blackspots', so that staff will not face disruption to their mobile internet signals even in the most built-up urban environments (See Exhibit 21). In the case of smart bins, robust mobile access to the internet would always be essential when trying to see the live data map of bins that have reached their thresholds, so as to figure out which were in urgent need of collection. Simon and his team know that these are ancillary, and act as 'enablers' in a sense, to helping reach waste management goals. On the other hand, alternative departments in the city council could directly gain from the benefits of these add-ons. For example, the smart city department's principles of work include "improving baseline connectivity" as a key indicator - where pervasive connectivity across the environment would help power the multiple internet of things use-cases (including smart waste management) that depended on it. Hence, smart bins that housed radio-cabinets, which improved mobile signals in area, would serve as an immense conduit for pervasive connectivity - helping the smart city department to achieve its objectives. Simon was also keen to note how the smart city department was instrumental in helping to kick-start this first smart bins services contract as part of the 'Smart Docklands' smart district. When looked at more holistically, the different departmental goals and key point indicators being 'socialised' between departments, could further stimulate synergy and motivation to trial such boundary-crossing technologies.

\section{The Decision Process}

Simon and his management team would have to consolidate these complexities, and synthesise them into coherent, logical, and equitable plans that meet the needs of the various stakeholders involved. Navigating the interplay among people, technology and processes would always be among the most important factors when determining the best course of action. This decision process could be broken down into the three primary categories of 1) Strategy; 2) Finances; and 3) Operational scale-up:

\section{Strategy}

\section{Further integration with corporate strategy}

The smart bin innovation services as mentioned, served the agendas of not just the waste management department of the city council, but others such as the smart city department and overarching goals of the chief executive's office. A closer look into aligning with overarching corporate goals could see reassessment on how individual departments are measured. In the case of the smart bins, being a purely efficient waste receptacle to becoming a multi-purpose vehicle that helped attain other departmental objectives, blurred the lines on whether key point indicators for city council functional departments would remain as they are. But this however, could take years of assessment and change management to fulfil. How does waste management justifiably channel resources from today's sole agenda of effective city sanitation services, into the actuation of other city council departmental goals? Likewise, all of it being done in anticipation of a macro trend that sees further integration with the city council's overall corporate strategy. 


\section{Finances}

\section{Commercial model to adopt}

The deployment choice that Simon and his team of managers decide upon would have to be underpinned by a fiscally sustainable commercial model. The commercial model adopted would have to establish definite financial and labour resource savings on a per annum basis at the very least. Additionally, the distinction made between capital and operational budgets within the city council currently sees a sway to procuring new innovative solutions through its capital budget, as opposed to 'leasing innovation' for a more flexible approach. Considering the increasing number of private sector exploratory business models, as well as changing commercial models being examined by the public sector, the current paradigm of the two distinct budgets could be ripe for re-evaluation. This however, goes beyond the jurisdiction of local government practice, what more a department within that local government entity. Simon and his team could thus, choose to operate within the existing paradigm, or look for alternatives construed as financially acceptable under the scrutinising eye of public audit. Simon and his team could also try to 'swim upstream' by pushing for higher-than-normal operational budgets for innovation, but in the process, risk losing access to an otherwise more available capital budget. Until the sway of opinion eventually bends to acknowledge, assess, and change these overarching budgetary practices as a whole, this seamless interplay and transfer (or its distilled transparency even) between operational and capital budgets concerning innovation may also take many years (if at all), for Ireland's public sector to enable.

\section{Operational scale-up}

\section{Grow smart bins in localised test-beds or smart districts only}

Simon and his team could choose to grow the number of smart bins, but only through leveraging localised test-beds as a means of growth. Test-beds such as Smart Docklands provide a 'living-lab' environment to trial different forms of innovative solutions and technologies, making it an ideal fit. In other words, to keep such breakthrough solutions like the smart bins, to locations where people expect them. Considering that the localised test-bed concept has grown to other districts around Dublin, such as Smart DCU (Dublin City University), Smart Sandyford (Business area), and Smart Balbriggan (Residential town area), the stakeholders involved with launching these new districts have generally bought into the benefits of deploying innovative solutions. It then makes sense to continue scaling up the use of smart bins in areas where there is fuller acceptance of such innovative technologies. Having such 'innovation champions' goes a long way to enabling use of solutions that potentially disrupt the usual flow of operations. Rollout in smart districts would also serve as ideal 'showcase' environments on a local, national, and international level, which could fuel the appetite of other areas and communities to adopt such innovative solutions.

The primary concern with scaling up solely through localised test-beds or smart districts however, is that they sit within the jurisdictions of several different entities, not all of which are under the purview of Dublin city council. For example, Smart DCU is steered by its own private university board, Smart Sandyford by the separate Dun Laoghaire Rathdown County Council, and Smart Balbriggan by the separate Fingal County Council. None of whose operations 'add' to the key point indicators of Dublin city council. This would hence, take decision-making out of the hands of Simon, his colleagues, and the councillors elect of Dublin city council. It would still however, contribute to the Dublin narrative as a whole, and ultimately benefit members of those new smart district communities. Additionally, keeping the smart bins only in test-bed districts conflict with public sentiments on wanting to see that 'reinvestment' and 'rejuvenation' happen in older urban areas. 


\section{Grow smart bins in highest footfall areas only}

With this option, Simon and team could appropriate the deployment of smart bins purely on a 'needs only' basis wherever high footfall (i.e. high density of pedestrian movement) is found - as a true mandate for using the higher capacity smart bins. Concentrating the rollout of smart bins in the city centre environment for example, would have the benefit of 24-hour staff rotations already in the area to attend to bins that reach capacity as well as react to rare incidences (like bin door handle damage or obstruction) in a much faster manner. The rollout in the city centre will also be able to showcase the 'fullest extent' of the smart bin value proposition. With an ecosystem that highlights its abilities of increased capacity and a fullness threshold indicator, this would help reduce the number of vehicles and operational staff in an already congested city centre at peak times. This would then allow the re-appropriation of (the already more numerous) waste collection staff assigned to the city centre, to the various other waste management work streams highlighted above.

The adoption of this scale up strategy however, would require the 'baselining' of what would constitute a high footfall area, and what areas would sit beneath that assigned threshold. This would require collection of data on pedestrian movement in the most likely of areas, and defining (through an evidence-based manner) areas with the highest density of movement. As a result, additional time and resources would be required to establish this approach properly. Additionally, the option of scaling up in high footfall areas may once again, come across as discriminatory when considering that alternative areas could be already be construed as being underserved. This perpetuation to only serve thriving hubs while leaving out the rest, would not be considered inclusive for a city council whose role is to provide for all members of Dublin's public.

\section{Hybrid mix of bins throughout the city}

A hybrid mix of smart bins and normal public bins may go on to address the concern of being inclusive to all areas and communities in Dublin city. Not concentrating benefits into key areas and adopting a distributed approach may help to evenly spread the benefits to all parts of society. This would also help in the distribution of productivity gains (i.e. saved manpower from waste collecting) across the multiple other waste management work streams and administrative areas as mentioned earlier. The hybrid approach will also enable flexibility to address specific requests, such as additional capacity in high demand and high complaint areas, as well as deployment in areas targeted for reinvestment and regeneration.

This approach however, as it suggests, loses the concentrated effects and ability to see the largest benefit gains from the solution. Waste collection staff would still have to upkeep the usual frequency of waste collection for the normal bins that sit among the smart bins. What could then evolve, would be a 'two tier system' of waste collection staff, where one group takes advantage of the needs only operations of the smart bins, while the other operates with the minimum daily collections currently seen with normal bins. This may go on to negate any of the perceived smart bin benefits, since it would not alleviate as much of the workload as advertised from normal waste collection operations.

\section{Replace all of Dublin city's over 3,000 public bins with smart bins}

A replacement for all the 3,000 public bins in the city would hypothetically, capture the largest benefits. A complete city ecosystem helping to reduce overall bin numbers, minimise frequency of collections, and thus re-appropriating operational staff to other waste management work streams on a city-wide scale. This could potentially see tremendous improvements to benchmarks on the other work streams such as general street cleaning, removal of illegal dumping, street washing, and many others as mentioned earlier. In 
other words, the productivity gains from waste collection, could see its largest transfers to overall waste management operations when adopted on such a scale.

Chief concerns to replacing the over 3,000 public bins as mentioned earlier, is how the unit economics simply does not add up considering the large financial costs associated with such a large-scale transition. The simplistic equation of 'replacing staff with smart bins' cannot easily be enacted due to the permanent nature of existing staff contracts, and the versatility of human labour (current inability to be replaced with automated technology). Likewise, the nature of replacing the sheer number of public bins, considering the number of staff already engaged with full-time schedules, would require a sequential approach over a dedicated time-frame, not unlike the earlier suggestions of first proceeding with either high footfall or other smart district areas. But what then after these first go-to locations? Should Simon and team then adopt the hybrid 'peppered' approach throughout the city? Or look to replace public bins in traditionally underserved areas as a counter-balance to such higher profile first rollouts? Alternatively, perhaps a simple 'clockwise deployment approach' could help defuse the potential favouritism debate?

Ultimately, each scale-up plan would have its own advantages and disadvantages to the affected communities, and would have to be assessed equitably. 


\section{Acknowledgements}

This case study relied on primary research interviews, as well as secondary research from existing online literature and corporate documentation from within Dublin city council. The in-depth analysis carried out for this case study could not have happened without the input of various members of the city council, in particular Simon Brock, Paul Arnold, Nicola Graham, and Mainard Gallagher. The authors also wish to acknowledge the Fulbright Commission and Lero Science Foundation Ireland for their support of the Fulbright Core Research Award that supported Dr. Mullarkey's work with Dublin City Council, National University of Ireland Maynooth, and Trinity College Dublin.

\section{Biographies}

Edward Emmanuel looks after project management and governance in Smart Docklands, the first flagship district of Smart Dublin - a collaboration of the four local authorities in Dublin to address urban challenges and opportunities through technology. Edward helps to drive key projects by ensuring their progress, deliverables, and milestones are achieved. He also shapes the governance processes and structures for the wider Smart Dublin team, helping to seed innovative pilot trials back into everday operational use for the municipality and its stakeholder partners. In addition to his work with Smart Dublin, since 2013, Edward has been helping international companies commercialise novel products and services in an array of industries and sectors that include Healthcare; Financial Services; Life Sciences; Environmental Sciences; Transportation; Energy Management; Agriculture; and Consumer Services. Harnessing core technology suites in Big Data; Artificial Intelligence; Cloud and Edge Computing; as well as the Internet of Things.

Jamie Cudden leads the development and implementation of Dublin City Council's Smart City strategy and ensures that the council takes advantage of the opportunity of technology innovation (Internet of Things, Big/Open Data) to drive better quality services and address priority city challenges in areas such as mobility/transport, environment and energy efficiency. He manages key relationships across industry, academia and government to promote and build out smart city solutions and demonstrators. He has extensive experience working across industry, local and central government to deliver projects that enhance Dublin's economic competitiveness. He currently holds the position of Company Secretary with ECO-UNESCO, a leading Irish environmental education charity that works with young people across Ireland. Jamie's qualifications include a science degree from Trinity College Dublin and a Masters in Geographic Information Science (GIS) from University College London. He previously worked in policy and technical advisory roles with Kensington and Chelsea Borough in London, Government office for London, the Home Office, Met Police and the Jill Dando Institute of Crime Science in the UK.

Matthew Mullarkey (Ph.D.) is the Director of the Doctor of Business Administration (DBA) Program for the USF Muma College of Business and an Instructor in the School of Information Systems and Management (SISM). Mullarkey is a 2019-2020 recipient of the Fulbright Scholar Award, 2018 recipient of the USF Faculty Externship Award, 2017 recipient of the USF Muma College of Business Outstanding Faculty Community Engagement Award, and 2015-2016 ISDS Undergraduate Teacher of the Year Award. Mullarkey's areas of research interest include design science research and action research in the evaluation and creation of information systems, smart cities, IoT, healthcare, social networking, and data science. Mullarkey teaches using case based discussions that engage Doctoral, MBA and MIS undergraduates in complex business decisions that typically involve a technology component. His service includes active engagement as an instructor, coach and mentor with start-up companies involved with USF Connect, Tampa Bay WAvE, Florida-Israel Business Accelerator, and the Greater Tampa Chamber of Commerce Start-up Scholars. Mullarkey works to integrate his business experience with the needs of the students, faculty and administration of the USF Muma College of Business in ways that contribute to student education, preparation for jobs, partnering with the Tampa Bay business community, and informs research with impact. 


\section{Exhibit 1 - Smart Docklands district}

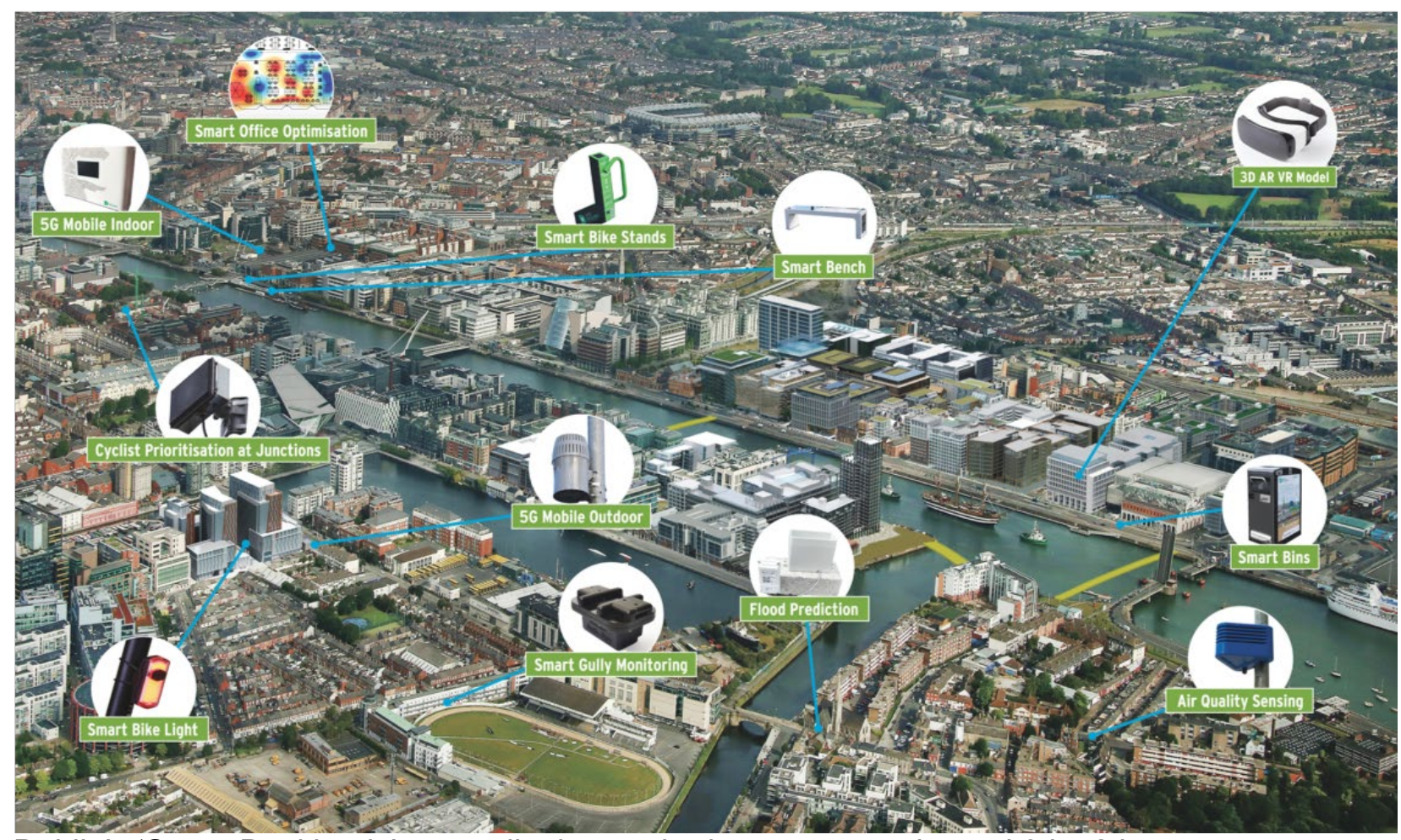

Dublin's 'Smart Docklands' smart district test-bed covers an estimated 3 by 2 km square area, which includes over 500 businesses and 25,000 residents, serving as a 'beating' commercial services hub for the city centre. The testbed allows the trialling and testing of multiple technologies to address urban challenges.

Source: Dublin City Council 


\section{Exhibit 2 - Smart Bin with Solar Panel that gives power to waste compacting function}
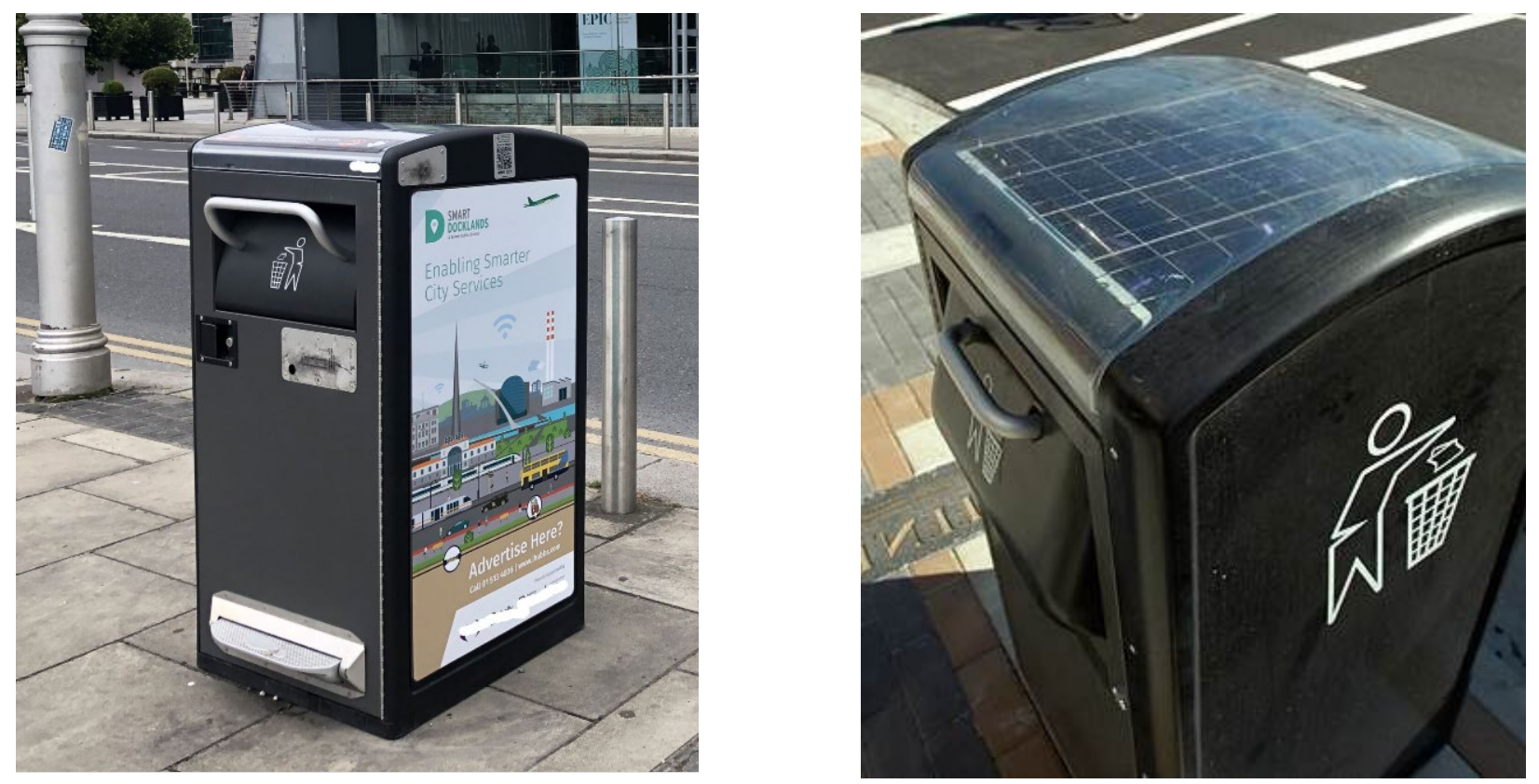

A deployed Smart Bin informing waste management when it has reached capacity, as well a holding up to 8 times the waste (800 litres) of your average public waste bin. Made possible through its internal waste compactor powered by attached solar panels.

Source: Dublin City Council (Left image) and Big Belly Bins (Right image) 


\section{Exhibit 3 - Waste management organisational chart}

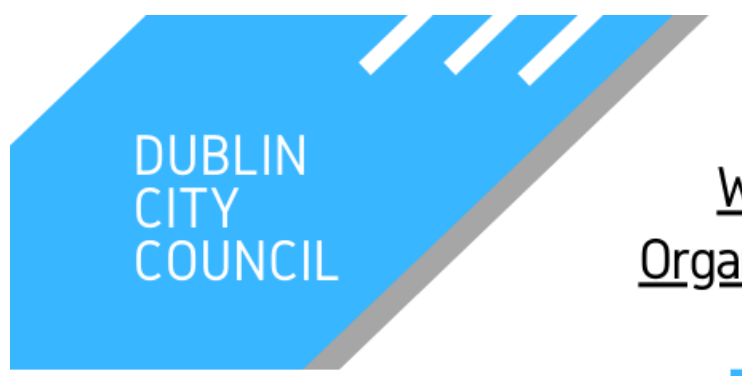

w. Comhairle Cathrach

Wublin City Council

\section{Waste Department Organisational Chart 2020 \\ DUBLIN COUNCIL}

(1)
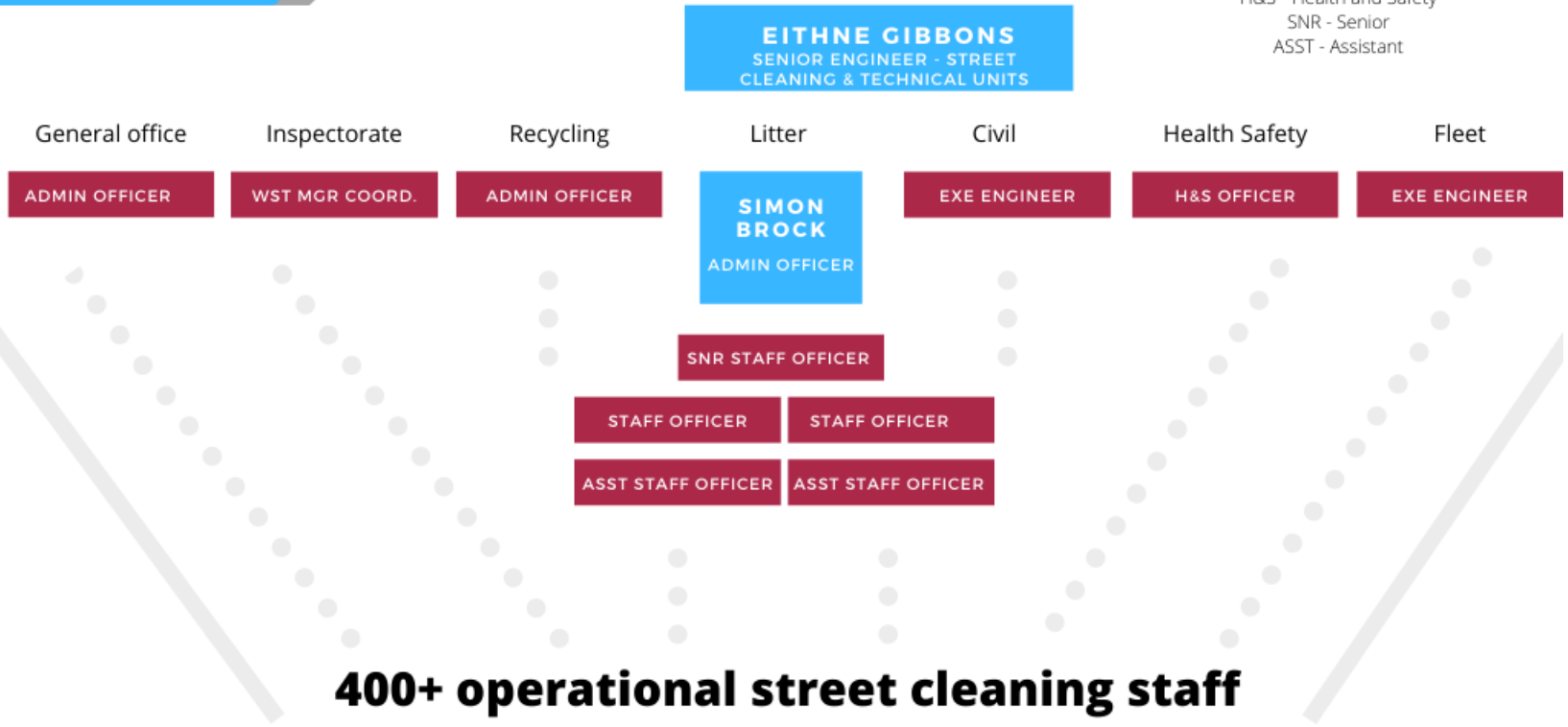

There are over 400 operatives carrying out various street cleaning functions, while not including local management, supervisory staff, enforcement staff, and maintenance. When including those, the overall total is closer to 490 staff members.

Source: Developed by case study author 


\section{Exhibit 4 - World's cities 10 billion tonnes of waste}

\section{World's Cities Produce up to 10 Billion Tonnes of Waste Each Year, UN Study Estimates}

Inadequate waste management has become a major public health, economic and environmental problem, with 7-10 billion tonnes of urban waste produced each year and 3 billion people worldwide lacking access to controlled waste disposal facilities, announces United Nations Environment Progamme in a new conducted study.

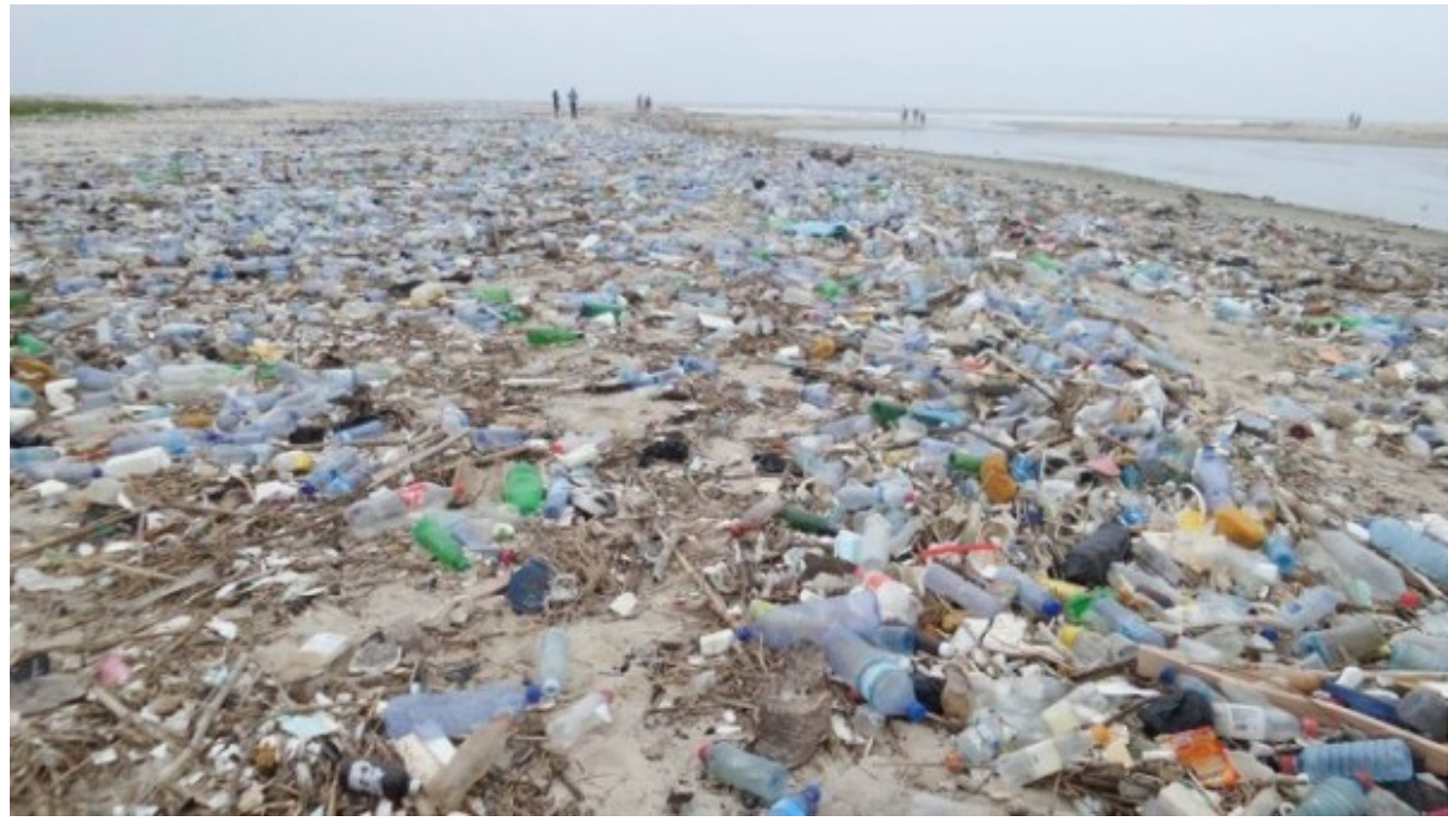

Fuelled by population growth, urbanization and rising consumption, the volumes of waste are likely to even double in lower-income African and Asian cities by 2030, warns the Global Waste Management Outlook - launched by the United Nations Environment Programme (UNEP) and the International Solid Waste Association (ISWA) today.

UNEP Executive Director Achim Steiner said, "An urgent response to the world's mounting waste problem is not only a public health and environmental necessity, but also a sound economic investment. Inaction is costing countries 5-10 times more than investments in proper waste management. A greater commitment by nations to systematically apply the 3 R's Reduce, Reuse, Recycle - can transform the problem of waste into a resource for our economies."

"The global waste management goals proposed by this report have the potential to result in dramatic reductions in greenhouse gases, the creation of millions of green jobs and economic 
benefits in the hundreds of billions of dollars. By achieving them, we would also be taking massive strides toward realizing the Sustainable Development Goals," he added.

The report offers an integrated global solution to the waste problem, including calling for immediate improvement of waste collection and disposal, preventing waste and maximizing reuse and recycling of resources. It also calls for a major shift away from the linear "take-makeuse-waste" economy and towards the circular "reduce-reuse-recycle" approach to the lifecycle of materials.

"This very first worldwide waste report really is a monumental work that has taken ISWA and UNEP experts two years to write," said David Newman, ISWA President, and added: "The Global Waste Management Outlook will help the waste management industry define its future over the next decade, and it also is an urgent call for action for investments to drive a global clean-up of the billions of tons of waste still dumped into our environment."

\section{We have the technological capacity to solve the global waste problem}

Dr. Oyun Sanjaasuren, President of the United Nations Environment Assembly (UNEA) said: "Collectively we have the technological capacity to solve the global waste problem. Despite of this, a staggering 3 billion people worldwide lack access to controlled waste disposal, with the result that wastes litter our streets with grave environmental and health consequences.

"This situation can be changed only if countries enforce proactive policies and sound institutions that encourage waste minimization and recycling" she added. "Major producers should also be more involved in managing the entire lifecycle of their products. International cooperation will be vital in preventing developing countries from becoming dumping ground for hazardous materials."

The report encourages a shift in thinking about waste as merely a health and environmental threat, towards a broader concept of resource management. It demonstrates how wisely managing both resources and waste, countries can cut costs of waste disposal and bring additional profit from the recovered raw materials.

\section{Belgium, Colombia and Kenya}

For example, the Belgian region of Flanders achieved the highest waste diversion rate in Europe, growing from nearly zero in the 1980 s to over 70 per cent in 2013 . This was possible with a smart mix of social, fiscal and legal policies, such as waste prevention education, establishing reuse centres and a "pay-as-you-throw" taxation system based on the "polluter pays" principle.

The report also cites numerous success stories from developing countries. For example, the inclusion of informal recyclers into the municipal waste management system in Bolivia resulted in the collection and treatment of 29,000 tonnes of waste and the creation of 443 green jobs. A 
similar scheme in Colombia's capital, Bogota, is diverting 1,200 tonnes of waste daily from the landfill and employing some 8,250 people.

In Kenya, a non-profit organization and the private sector are running separate initiatives to treat the country's e-waste. Between them, they process up to 30 tonnes of e-waste per month and market the recovered materials, while safely disposing of the hazardous wastes. Both facilities are fast approaching self-sustainability, proving that safe recycling can be a successful business model in developing countries as well.

The Global Waste Management Outlook was jointly prepared by UNEP's International Environmental Technology Centre (IETC) and the International Solid Waste Association (ISWA) and was launched during ISWA's 2015 World Congress in Antwerp. Get the report here.

Source: UN Environment Programme 


\section{Exhibit 5 - Annual waste per capita globally}

\begin{tabular}{|l|l|l|l|l|l|}
\hline $0-0.49$ & $0.50-0.99$ & No data
\end{tabular}

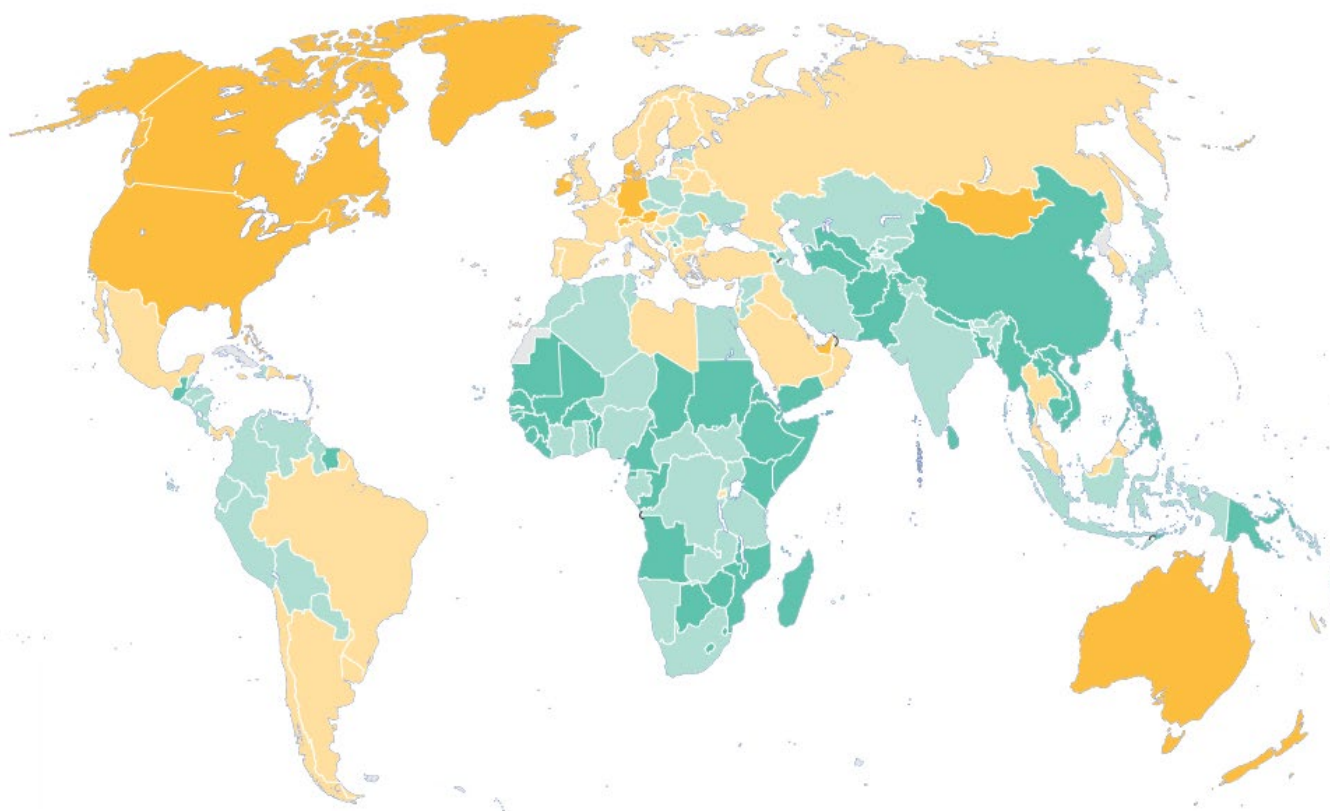

The amount of solid waste generated per capita has seen some correlation with prosperity of countries and rapid urbanisation, where waste management incurs among the biggest expenditure for local government administrations.

Source: World Economic Forum 


\section{Exhibit 6 - Waste produced in Ireland}

$3 \mathrm{M}$

Source: EPA

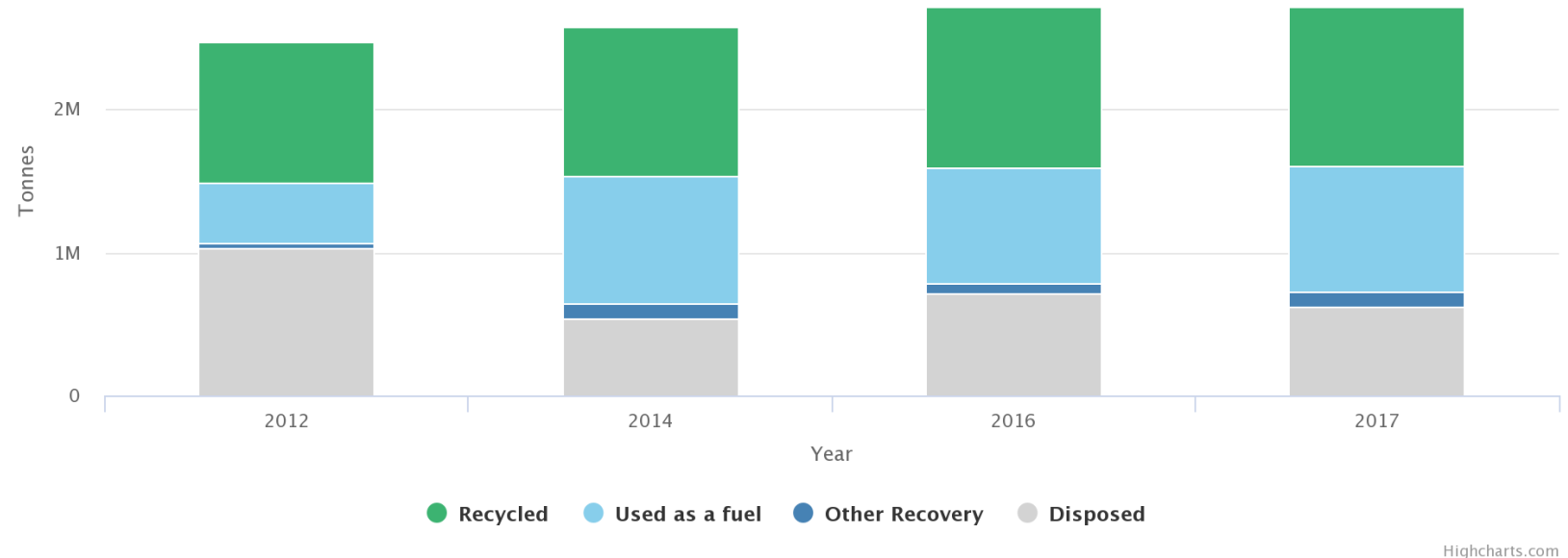

The average amount of waste produced per person in 2016 was $580 \mathrm{~kg}$ of municipal waste well above the European average of $487 \mathrm{~kg}$ per person.

Source: Environmental Protection Agency (EPA) Ireland 


\section{Exhibit 7 - Operational areas in Dublin city}

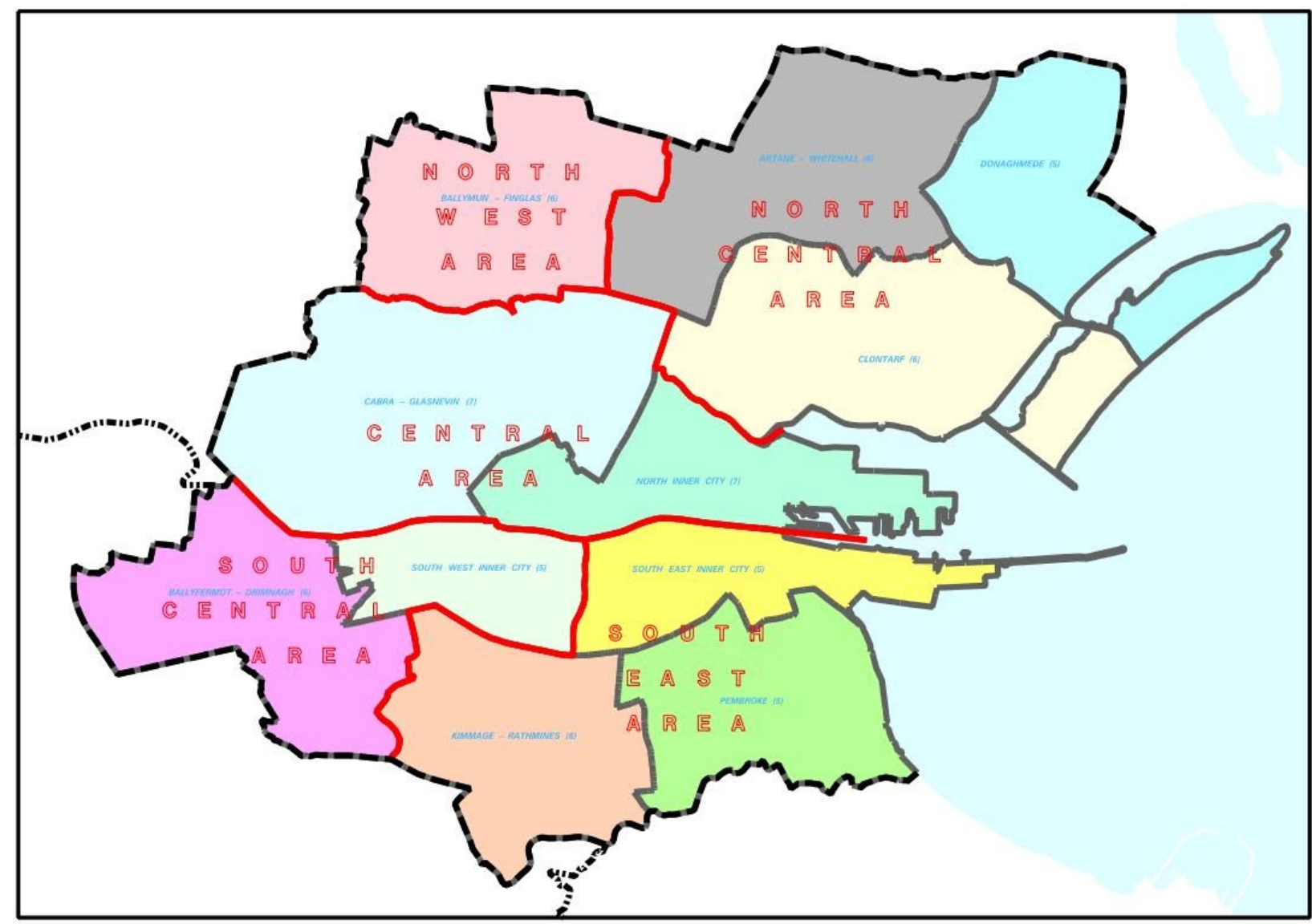

There are 5 administrative areas in Dublin city council, with an additional operational area in the city centre that functions 24 hours a day for waste management activities.

Source: Dublin City Council 


\section{Exhibit 8 - Side-loader caged vehicle for waste collection}

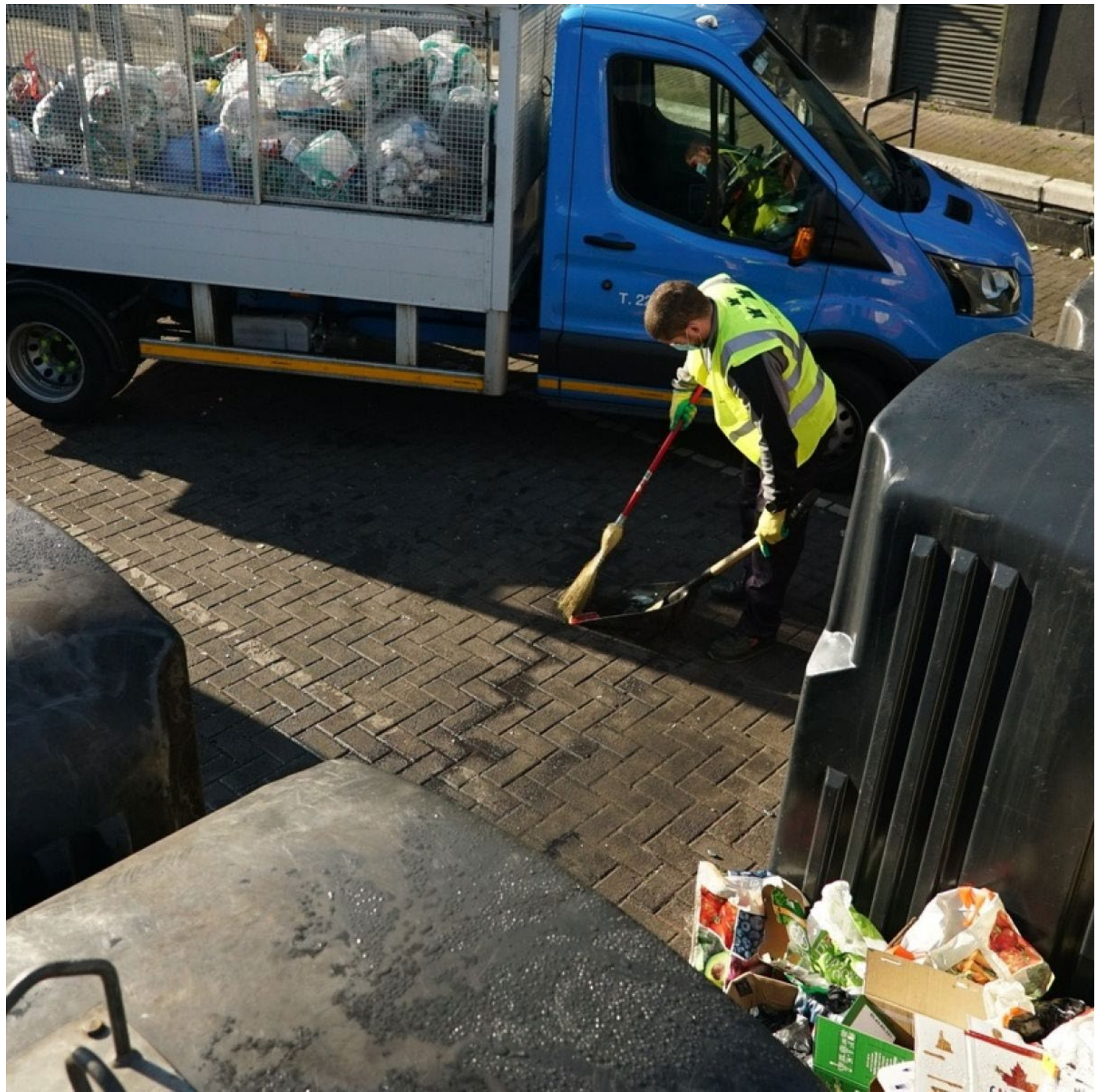

Side loader caged vehicles used to collect public waste in Dublin city.

Source: Dublin City Council 


\section{Exhibit 9 - Large RCV truck}

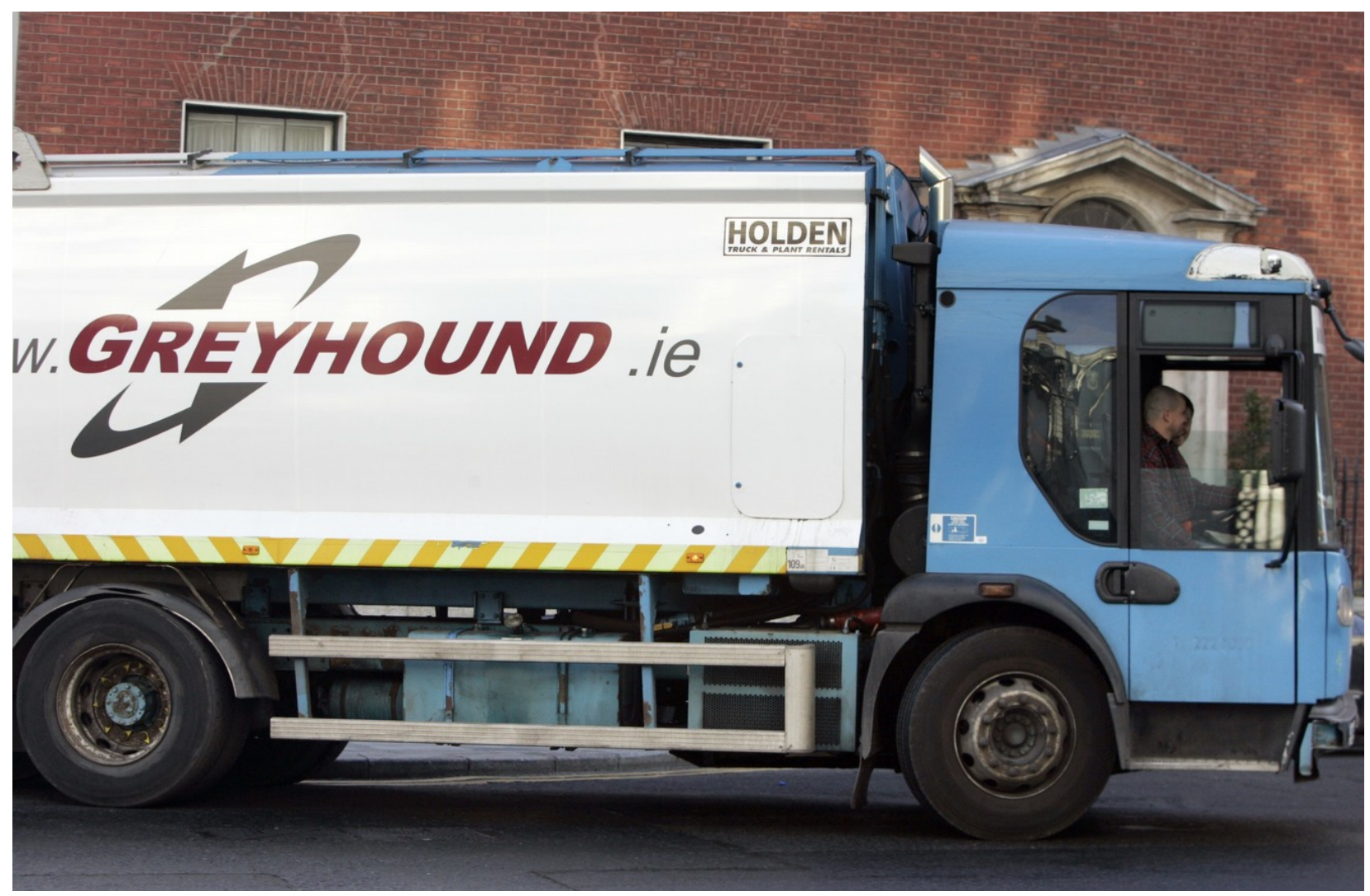

Refuse Collection Vehicles (RCV) are generally too large to turn into the narrow Dublin city lanes.

Source: Dublin City Council 


\section{Exhibit 10 - Open-air public pin}

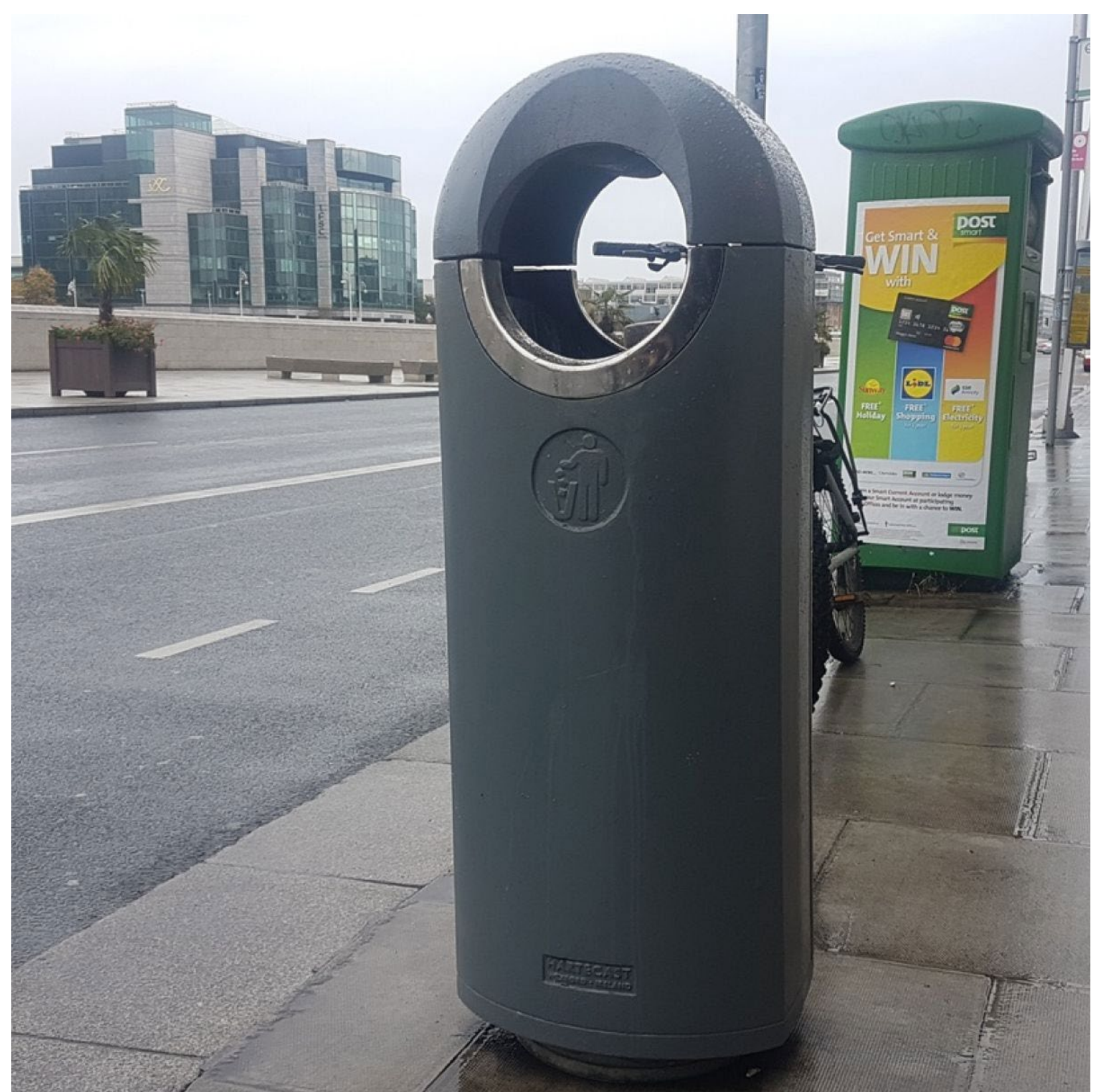

A vast majority of public bins in Dublin city adopt an 'open air' concept to facilitate ease of waste disposal from the public.

Source: Dublin City Council 


\section{Exhibit 11 - Smart bin foot pedal}

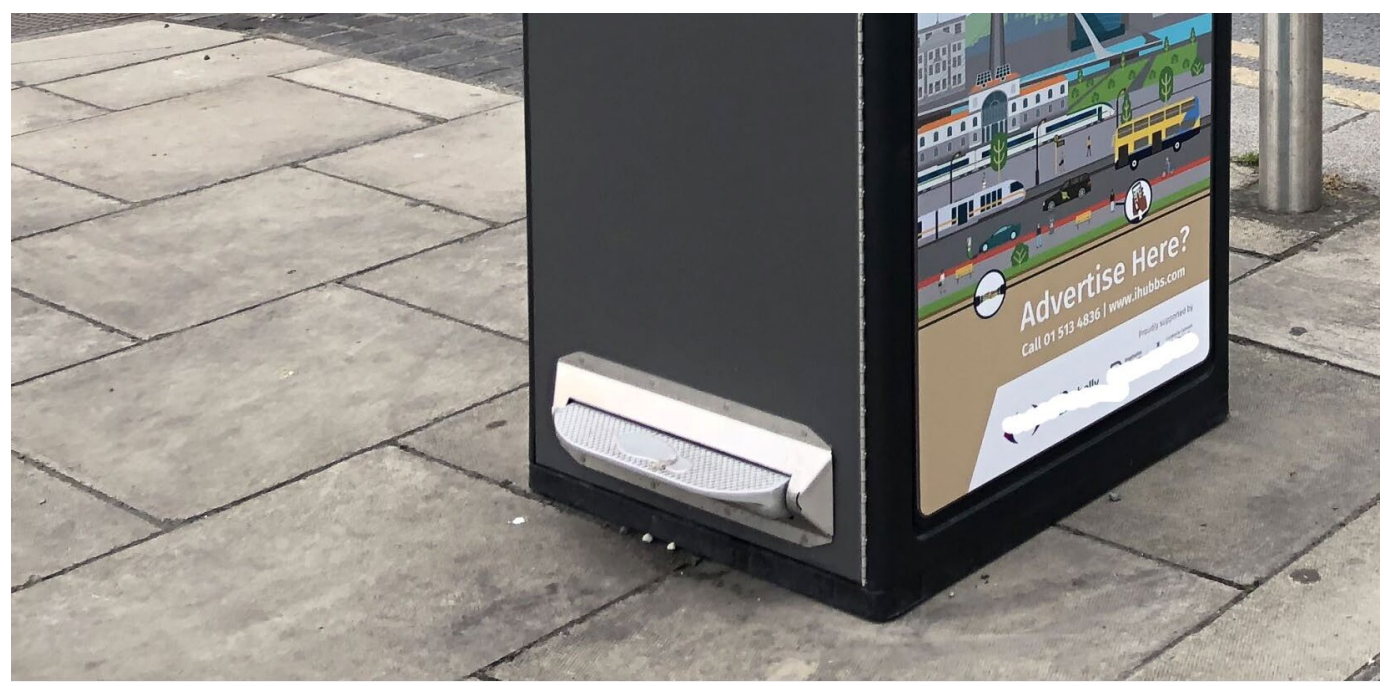

Upon feedback from the public, a simple connected foot pedal was installed, acting as a mechanism to open the smart bin's door handle to deposit waste, without having to use your hands pull it open.

Source: Dublin City Council 


\section{Exhibit 12 - Public feedback on waste management priorities}

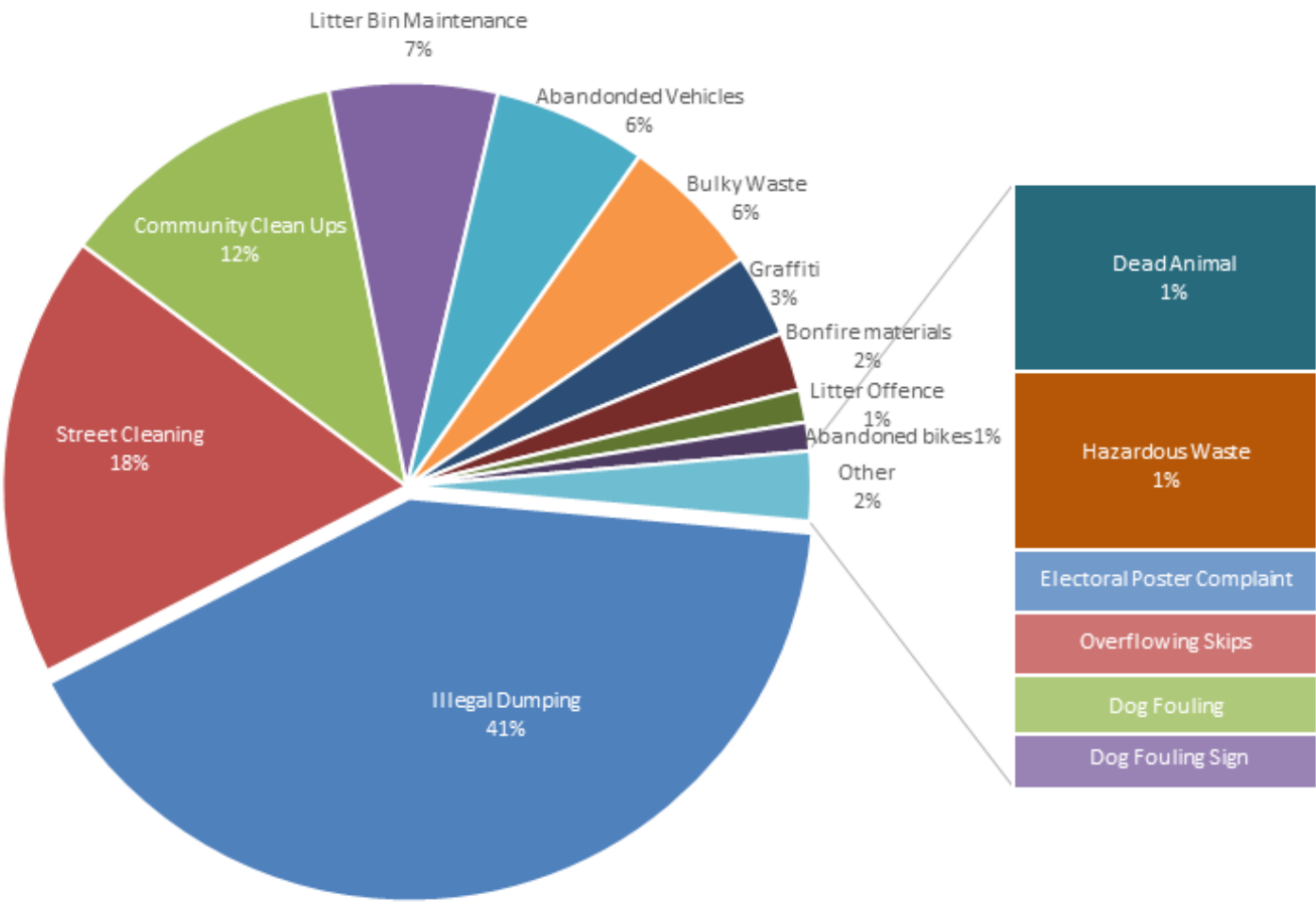

The feedback and complaints by type, received for year 2018, indicates illegal dumping as a the leading concern among members of Dublin's public.

Source: Dublin City Council 


\section{Exhibit 13 - QR code on normal bin}

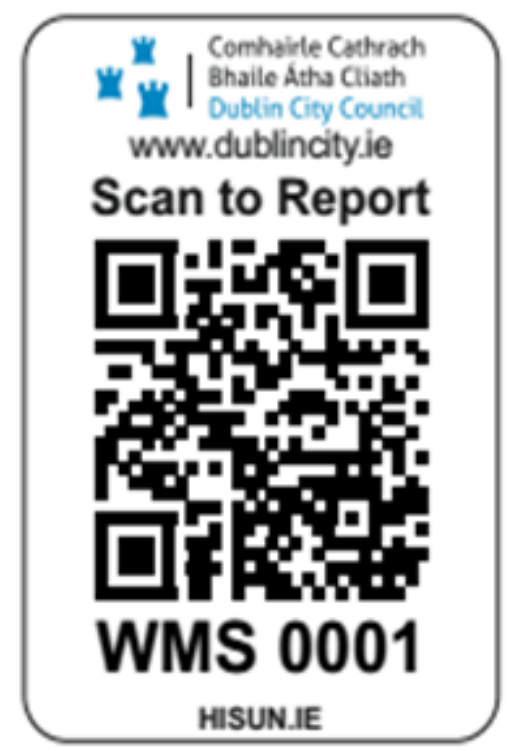

The unique QR code provided for each public bin in Dublin city helps to provide an additional feedback channel to the waste department on each bin's physical state.

Source: Dublin City Council 


\section{Exhibit 14 - Smart bin digital dashboard}

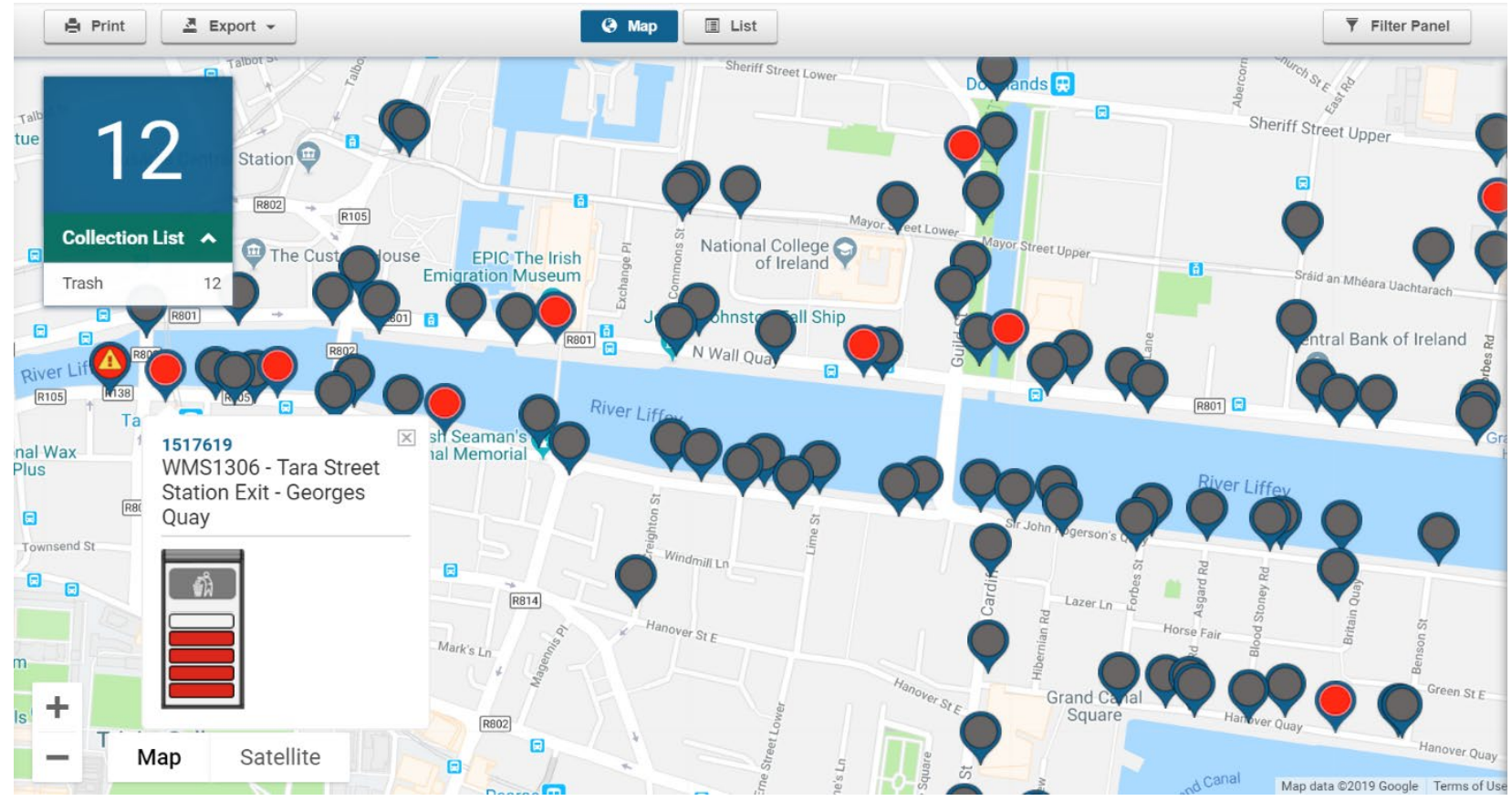

The digital map of smart bins in the Smart Docklands district, highlighting bins that are about to reach their capacity through the red colour-coded indicators. The example of bin WMS1306 in Tara Street has reached $80 \%$ capacity.

Source: Dublin City Council 
Exhibit 15 - Reduced collection frequency with smart bins

\section{RESULT TO DATE $85 \%$ REDUCTION IN COLLECTIONS}

Based on previous bin collection system of 78 bins emptied an average of 2 times per day

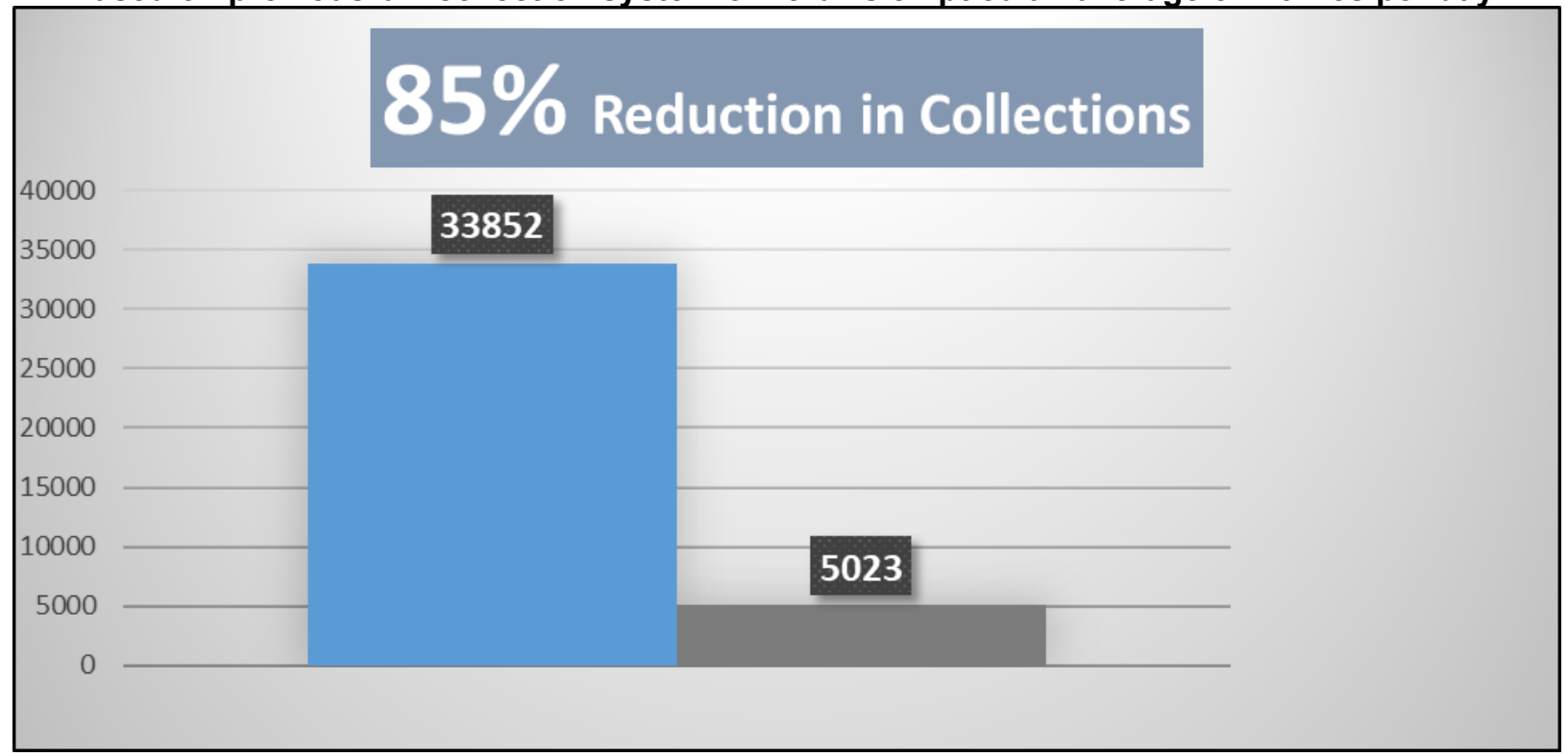

The Smart Bins recorded as much as an $85 \%$ reduction in collections in the Smart Docklands district over an estimate 7-month period (February to August 2019), compared to predicted operations had normal waste bins been in place.

Source: Dublin City Council 


\section{Exhibit 16 - Advertising revenues}

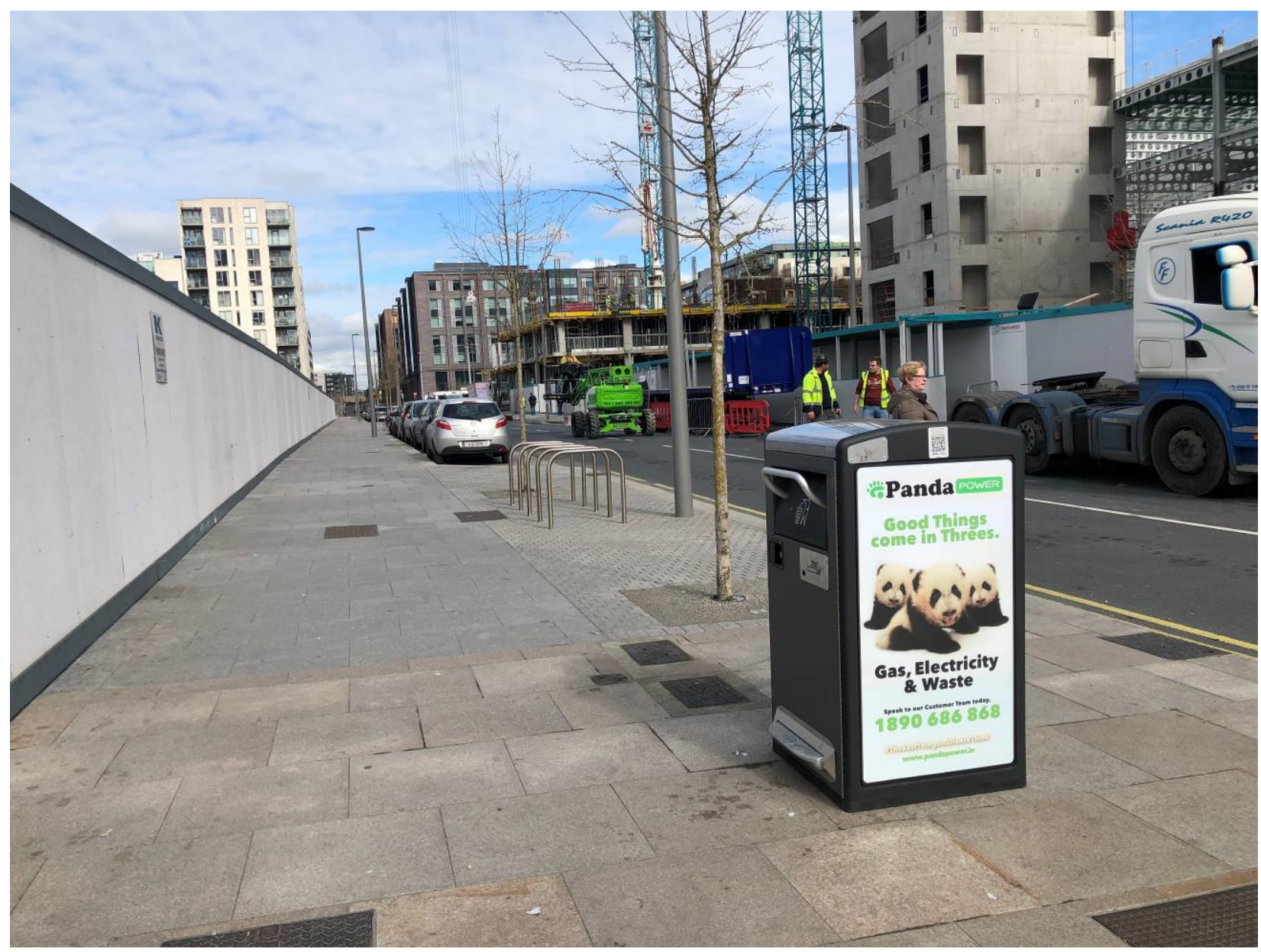

Smart Bin with advertising space on its sides. The revenue gained from such advertising can be shared with the local government body as a means to alleviate its annual leasing fee.

Source: Dublin City Council 


\section{Exhibit 17 - Add-on sensors}
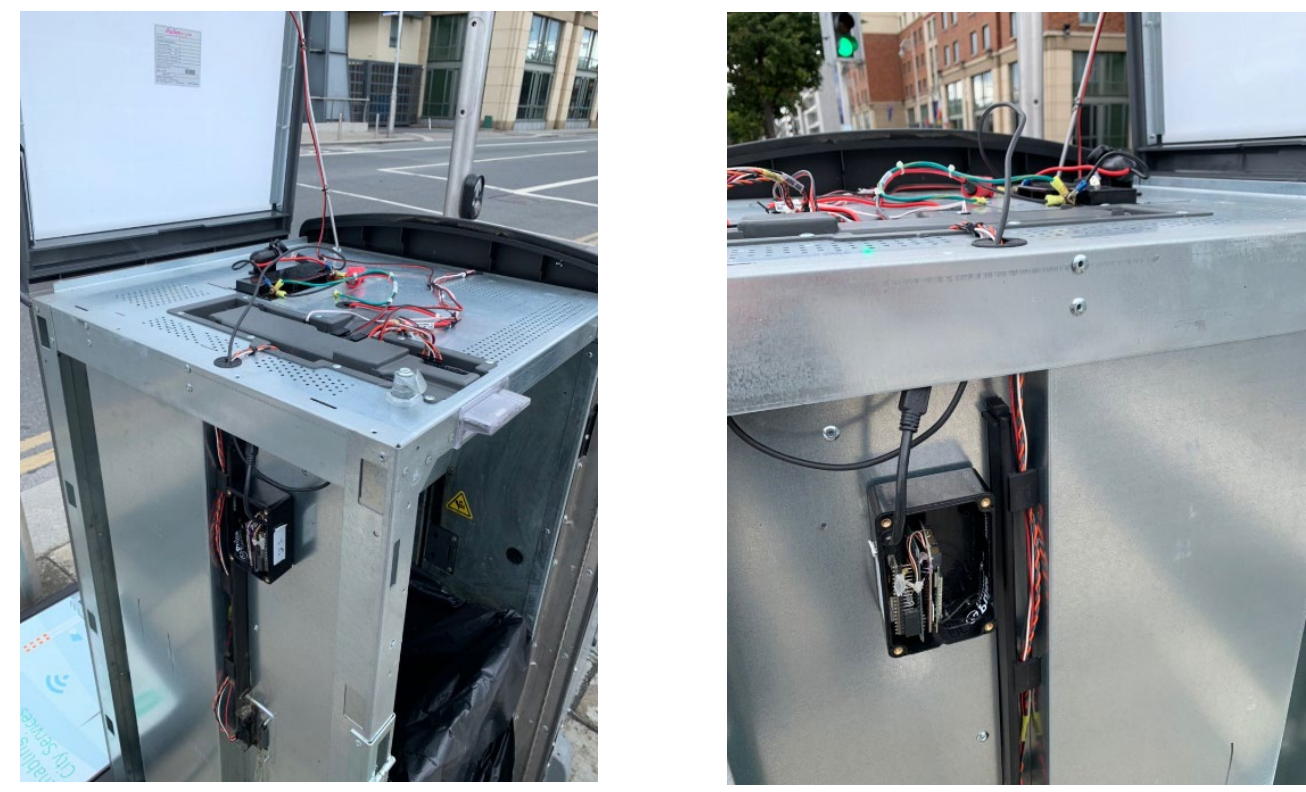

The Smart Bins are now able to 'power' additional loT sensors such as this attached footfall counter, which can help indicate the density of people in the area, at specific times of the day.

Source: Dublin City Council 


\section{Exhibit 18 - Telecom equipment hosting}
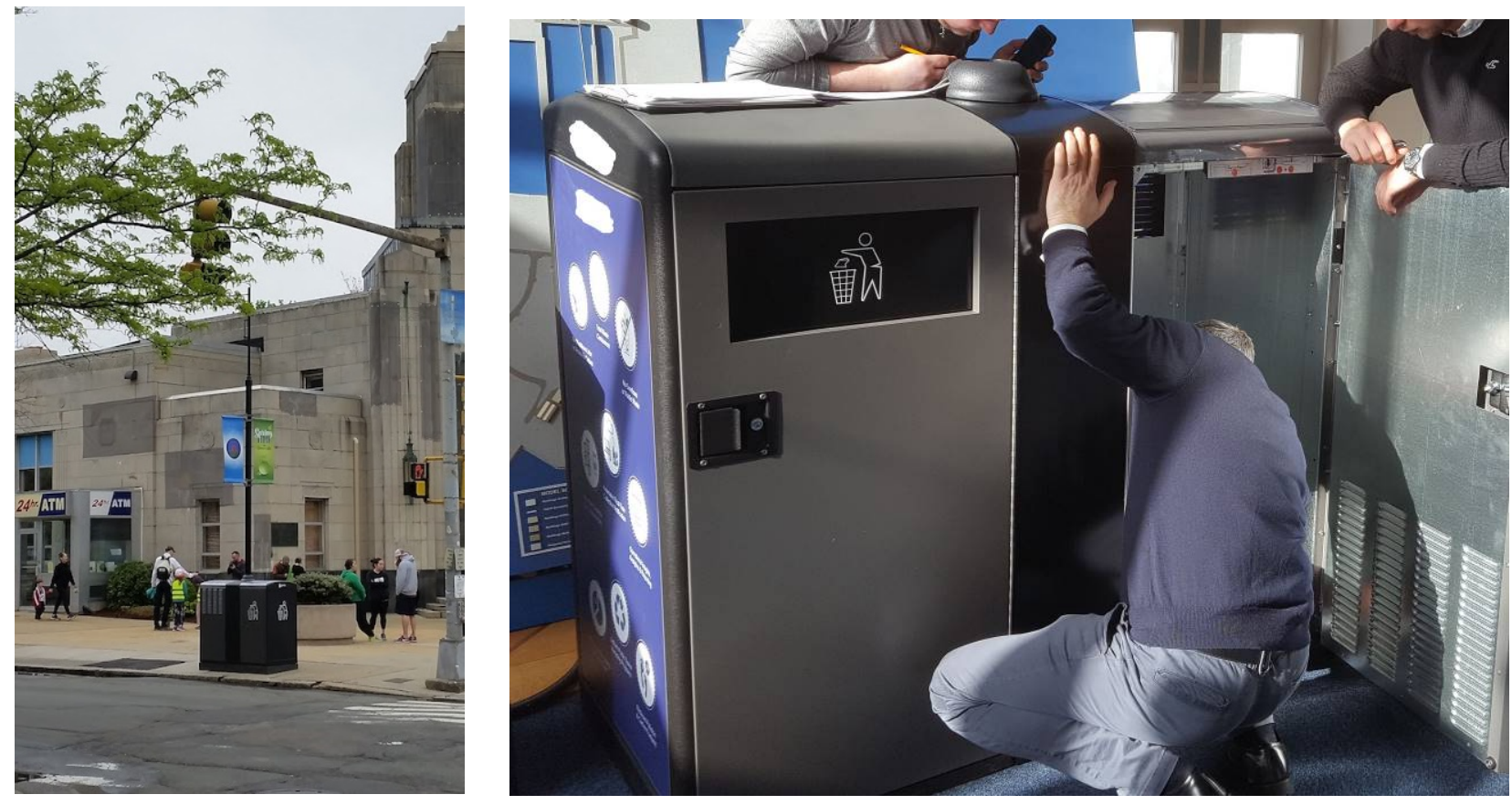

The Smart Bins are now also able to host telecom equipment including a mast with antenna. When set up correctly, such infrastructure placed in key locations will help to alleviate 'mobile data congestion' from the crowds.

Source: Big Belly Bins (Left image) and Dublin City Council (Right image) 


\section{Exhibit 19 - Wifi services}

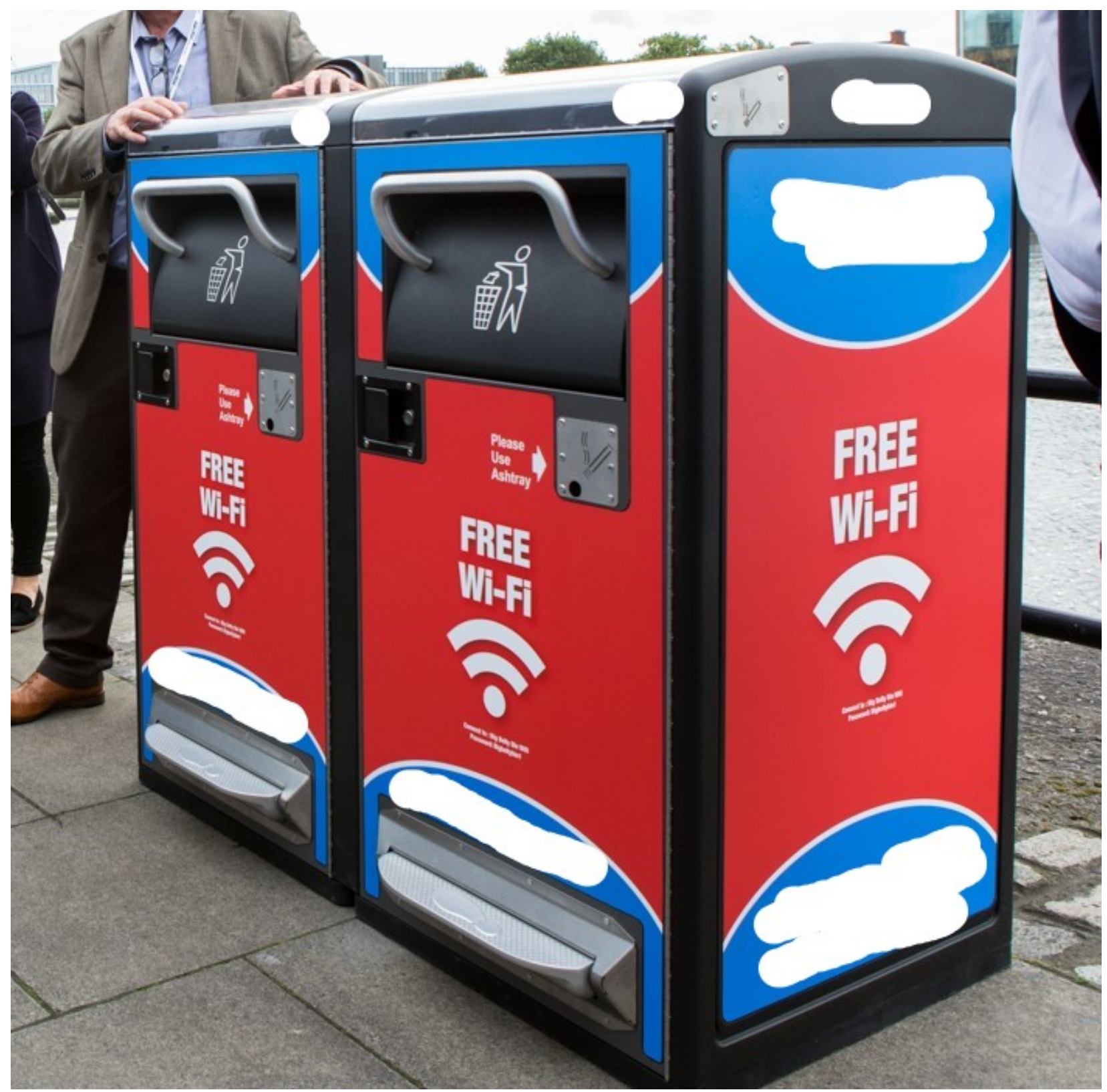

The Smart Bins are now also able to provide WiFi connectivity with add-ons, giving individuals such as tourists important internet connectivity when they lack access to mobile data in an area.

Source: Dublin City Council 
Exhibit 20 - Capital expenditure from years 2020 to 2022

\begin{tabular}{|c|c|c|c|c|}
\hline \multicolumn{5}{|l|}{ Projects Contractually Committed to } \\
\hline Projects Not Contractually Committed to & \multicolumn{4}{|c|}{ EXPENDITURE 2020-2022 } \\
\hline & $\begin{array}{c}\text { Expected } \\
\text { Expenditure } \\
2020\end{array}$ & $\begin{array}{c}\text { Expected } \\
\text { Expenditure } \\
2021\end{array}$ & $\begin{array}{c}\text { Expected } \\
\text { Expenditure } \\
2022\end{array}$ & $\begin{array}{r}\text { Expected } \\
\text { Expenditure } \\
2020-2022\end{array}$ \\
\hline WASTE MANAGEMENT & & & & \\
\hline DUBLIN DISTRICT HEATING - PHASE 2 & $10,359,000$ & $25,559,000$ & $13,276,000$ & $49,194,000$ \\
\hline PURCHASE OF SOLAR COMPACTOR BINS & 200,000 & 250,000 & & 450,000 \\
\hline R139 CLEAN UP & $6,000,000$ & & & $6,000,000$ \\
\hline TOTAL - WASTE MANAGEMENT & $16,559,000$ & $25,809,000$ & $13,276,000$ & $55,644,000$ \\
\hline
\end{tabular}

Innovation through capital expenditure has been the usual route for municipality departments, including this approved capital budget for waste management to purchase more smart bins (named here as Solar Compactor Bins).

Source: Dublin City Council 


\section{Exhibit 21 - Mobile blackspots}

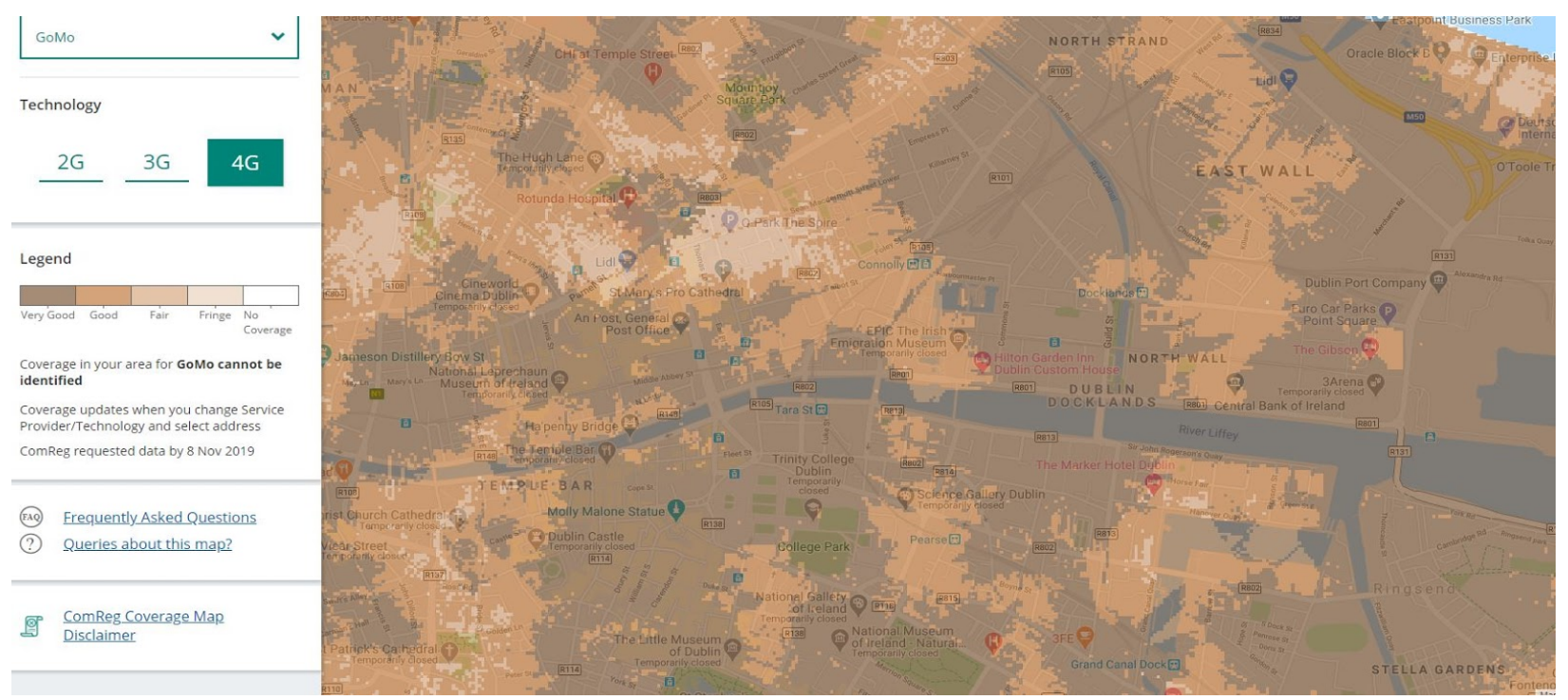

Here we see clearly that coverage is not in the 'very good' range of quality for all parts of Dublin's city centre, which may affect services that depend on mobile coverage to function seamlessly. Coverage is also dependant on mobile operator provider. In this instance, it is 'GoMo'.

Source: Commission for Communications Regulation (ComReg) Ireland 